\title{
HCOOH distributions from IASI for 2008-2014: comparison with ground-based FTIR measurements and a global chemistry-transport model
}

\author{
Matthieu Pommier ${ }^{1, a}$, Cathy Clerbaux ${ }^{1,2}$, Pierre-François Coheur ${ }^{2}$, Emmanuel Mahieu ${ }^{3}$, Jean-François Müller ${ }^{4}$, \\ Clare Paton-Walsh ${ }^{5}$, Trissevgeni Stavrakou ${ }^{4}$, and Corinne Vigouroux ${ }^{4}$ \\ ${ }^{1}$ LATMOS/IPSL, UVSQ Université Paris-Saclay, UPMC, CNRS, Guyancourt, France \\ ${ }^{2}$ Spectroscopie de l'Atmosphère, Chimie Quantique et Photophysique, Université Libre de Bruxelles (ULB), \\ Brussels, Belgium \\ ${ }^{3}$ Institute of Astrophysics and Geophysics of the University of Liège, Liège, Belgium \\ ${ }^{4}$ Royal Belgian Institute for Space Aeronomy (BIRA-IASB), Avenue Circulaire 3, 1180 Brussels, Belgium \\ ${ }^{5}$ School of Chemistry, University of Wollongong, Wollongong, Australia \\ anow at: Norwegian Meteorological Institute, Oslo, Norway
}

Correspondence to: Matthieu Pommier (matthieup@met.no)

Received: 27 January 2016 - Published in Atmos. Chem. Phys. Discuss.: 1 March 2016

Revised: 6 June 2016 - Accepted: 24 June 2016 - Published: 21 July 2016

\begin{abstract}
Formic acid ( $\mathrm{HCOOH})$ is one of the most abundant volatile organic compounds in the atmosphere. It is a major contributor to rain acidity in remote areas. There are, however, large uncertainties on the sources and sinks of $\mathrm{HCOOH}$ and therefore $\mathrm{HCOOH}$ is misrepresented by global chemistry-transport models. This work presents global distributions from 2008 to 2014 as derived from the measurements of the Infrared Atmospheric Sounding Interferometer (IASI), based on conversion factors between brightness temperature differences and representative retrieved total columns over seven regions: Northern Africa, southern Africa, Amazonia, Atlantic, Australia, Pacific, and Russia. The dependence of the measured $\mathrm{HCOOH}$ signal on the thermal contrast is taken into account in the conversion method. This conversion presents errors lower than $20 \%$ for total columns ranging between 0.5 and $1 \times 10^{16}$ molec $\mathrm{cm}^{-2}$ but reaches higher values, up to $78 \%$, for columns that are lower than $0.3 \times 10^{16}$ molec $\mathrm{cm}^{-2}$. Signatures from biomass burning events are highlighted, such as in the Southern Hemisphere and in Russia, as well as biogenic emission sources, e.g., over the eastern USA. A comparison between 2008 and 2014 with ground-based Fourier transform infrared spectroscopy (FTIR) measurements obtained at four locations (Maido and Saint-Denis at La Réunion, Jungfraujoch, and
\end{abstract}

Wollongong) is shown. Although IASI columns are found to correlate well with FTIR data, a large bias (>100\%) is found over the two sites at La Réunion. A better agreement is found at Wollongong with a negligible bias. The comparison also highlights the difficulty of retrieving total columns from IASI measurements over mountainous regions such as Jungfraujoch. A comparison of the retrieved columns with the global chemistry-transport model IMAGESv2 is also presented, showing good representation of the seasonal and interannual cycles over America, Australia, Asia, and Siberia. A global model underestimation of the distribution and a misrepresentation of the seasonal cycle over India are also found. A small positive trend in the IASI columns is observed over Australia, Amazonia, and India over the 20082014 period (from 0.7 to $1.5 \%$ year $^{-1}$ ), while a decrease of $\sim 0.8 \%$ year $^{-1}$ is measured over Siberia.

\section{Introduction}

Formic acid ( $\mathrm{HCOOH})$ is among the most abundant volatile organic compounds (VOCs) present in the atmosphere. Along with acetic acid it is a major contributor to the acidity of precipitation, especially in remote regions (Keene and 
Galloway, 1988; Andreae et al., 1988). HCOOH has small direct emissions from vegetation (Keene and Galloway, 1984, 1988), ants (Graedel and Eisner, 1988), biomass burning (e.g., Goode et al., 2000), soils (Sanhueza and Andreae, 1991), agriculture (e.g., Ngwabie et al., 2008), and motor vehicles (Kawamura et al., 1985; Grosjean, 1989) but is mainly a secondary product from other organic precursors. The largest global chemical sources of $\mathrm{HCOOH}$ include isoprene, monoterpenes, other terminal alkenes (e.g., Neeb et al., 1997; Lee et al., 2006; Paulot et al., 2011), alkynes (Hatakeyama et al., 1986; Bohn et al., 1996), and acetaldehyde (Andrews et al., 2012; Clubb et al., 2012). $\mathrm{HCOOH}$ is mainly removed from the troposphere through wet and dry deposition and to a lesser extent through oxidation by the $\mathrm{OH}$ radical.

$\mathrm{HCOOH}$ is a short-lived species and its lifetime is mainly determined by the precipitation rate. The lifetime ranges between 2 days during the rainy season and 6 days in the dry season in the boundary layer (Sanhueza et al., 1996). The global lifetime in the troposphere is 3-4 days (Paulot et al., 2011; Stavrakou et al., 2012). Photochemical loss is relatively slow ( $\tau \sim 25$ days), so that any $\mathrm{HCOOH}$ formed or vented outside of the boundary layer can be transported over long distances in the free troposphere (Paulot et al., 2011).

Our knowledge about sources and sinks of $\mathrm{HCOOH}$ is still incomplete despite the numerous studies that have been published during the last decade. In current emissions inventories, such as the biogenic emission inventory MEGANMACC (Sindelarova et al., 2014), the main source regions are located in tropical regions as presented in Fig. 1 for the period between 2008 and 2010. A recent work shows a possible source of $\mathrm{HCOOH}$ over the Arctic Ocean (Jones et al., 2014). The study by Stavrakou et al. (2012) highlights a misrepresentation of emissions from tropical and boreal forests in models compared to total columns retrieved from Infrared Atmospheric Sounding Interferometer (IASI) observations by Razavi et al. (2011). Millet et al. (2015), Paulot et al. (2011), and Stavrakou et al. (2012) point to the existence of one or more large missing sources. These studies suggest an important gap in our current understanding of hydrocarbon oxidation and/or the existence of unknown direct fluxes of $\mathrm{HCOOH}$.

Nadir-looking atmospheric sensors allow us to derive global distributions for trace gases, with a limited vertical sensitivity as compared to airborne or ground-based measurements. Their extended spatial coverage allows the observing of remote regions which are sparsely studied by field campaigns. Only a few satellites provide tropospheric $\mathrm{HCOOH}$ observations, such as the nadir-viewing instrument IASI (e.g., Razavi et al., 2011) and the Tropospheric Emission Spectrometer (TES) (e.g., Cady-Pereira et al., 2014). The Michelson Interferometer for Passive Atmospheric Sounding (MIPAS) limb instrument provided monthly global distributions of $\mathrm{HCOOH}$ around $10 \mathrm{~km}$ (Grutter et al., 2010), and the solar-occultation Atmospheric Chemistry Experi-

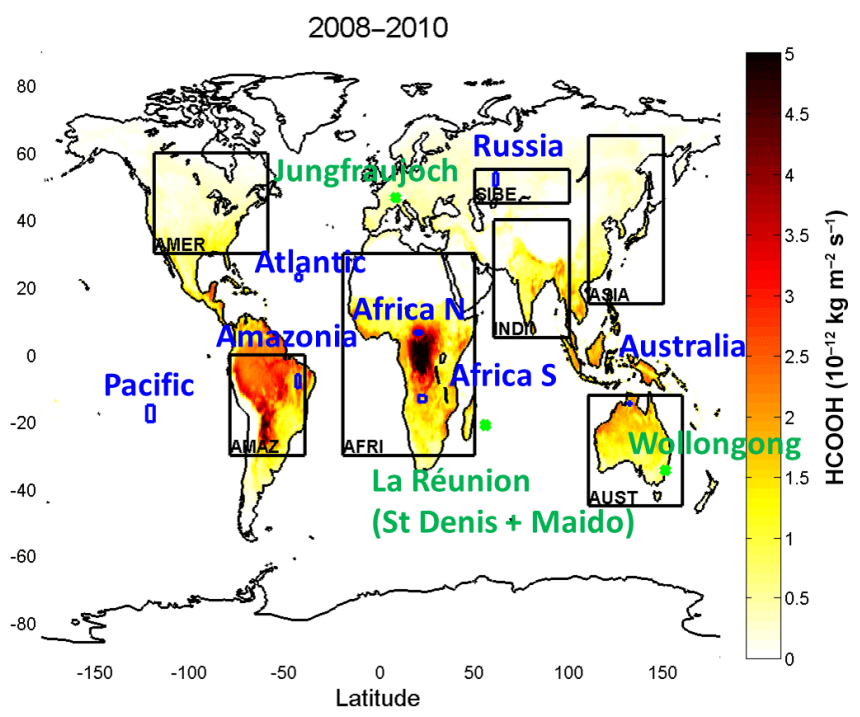

Figure 1. MEGAN-MACC HCOOH emissions for the period between 2008 and 2010 on a $0.5^{\circ} \times 0.5^{\circ}$ grid. The green stars correspond to the location of the FTIR measurements, the seven selected regions used for the retrievals and described in Table 1 are highlighted in blue, and the black boxes are the regions used for the comparison with IMAGESv2.

ment (ACE) provides seasonal global distribution in the upper troposphere (e.g., González Abad et al., 2009).

The data used in this study are provided by IASI. This instrument has two important advantages: a low radiometric noise and a high spatial coverage. $\mathrm{HCOOH}$ is a weak absorber, so it is a challenge to retrieve total columns from the IASI radiance. Global distributions of $\mathrm{HCOOH}$ over land were initially derived using a method based on brightness temperature difference and using forward simulations (Razavi et al., 2011). More recently, R'Honi et al. (2013) developed a specific method to study extreme events occurring during the large fires in Russia during the summer 2010. These studies, however, highlighted discrepancies between the retrieved distributions and especially within enriched $\mathrm{HCOOH}$ air masses as, for instance, over large forest fires. Indeed, the total columns from R'Honi et al. (2013) were on average a factor of 2 lower than in Razavi et al. (2011) (around a factor of 1.5 for columns higher than $5 \times 10^{16}$ molec $\mathrm{cm}^{-2}$ and 2.3 for columns lower than $5 \times$ $10^{16} \mathrm{molec}^{-2}$ ). In this paper, we present an update of the method used in Razavi et al. (2011), in order to derive $\mathrm{HCOOH}$ distributions over both land and sea, suitable for both enhanced and background concentrations over the period 2008-2014. Section 2 introduces the IASI mission and explains the methodology used, based on an optimal estimation method (OEM) retrieval over selected areas, used to design a fast retrieval methodology based on the brightness temperature difference and conversion factors. In Sect. 3, global distributions are shown; the products are compared 
Table 1. Selected regions used for the retrieval. The localization of each area and the number of spectra retrieved during the studied period are provided. The numbers correspond to the total number of successfully retrieved spectra and those given in parentheses to the total number of spectra in each region.

\begin{tabular}{llr}
\hline Region & Localization & $\begin{array}{r}\text { Number of } \\
\text { retrieved spectra }\end{array}$ \\
\hline Northern Africa & $6-7^{\circ} \mathrm{N}, 18-22^{\circ} \mathrm{E}$ & $265(358)$ \\
Southern Africa & $12-14^{\circ} \mathrm{S}, 20-24^{\circ} \mathrm{E}$ & $788(1083)$ \\
Amazonia & $6-10^{\circ} \mathrm{S}, 43-45^{\circ} \mathrm{W}$ & $682(739)$ \\
Atlantic & $22-24^{\circ} \mathrm{N}, 42-45^{\circ} \mathrm{W}$ & $675(737)$ \\
Australia & $14-15^{\circ} \mathrm{S}, 131-133^{\circ} \mathrm{E}$ & $218(271)$ \\
Pacific & $20-22^{\circ} \mathrm{S}, 140-142^{\circ} \mathrm{E}$ & $472(492)$ \\
Russia & $50-54^{\circ} \mathrm{N}, 60-62^{\circ} \mathrm{E}$ & $538(781)$ \\
\hline
\end{tabular}

to ground-based measurements and to the global chemistrytransport model (CTM) IMAGESv2, providing an analysis of the seasonal and interannual variability of $\mathrm{HCOOH}$ columns. The conclusions are given in Sect. 4.

\section{IASI HCOOH columns}

\subsection{The IASI mission}

IASI is a nadir-viewing Fourier transform spectrometer instrument. Currently two instruments are in orbit. The first model was launched on board the MetOp-A platform in October 2006 providing now more than 8 years of observations. The second instrument was launched in September 2012. Owing to its wide swath, each instrument delivers near global coverage twice per day at around 09:30 and 21:30 local time. IASI measures in the thermal infrared part of the spectrum, between 645 and $2760 \mathrm{~cm}^{-1}$. It records radiance from the Earth's surface and the atmosphere with an apodized spectral resolution of $0.5 \mathrm{~cm}^{-1}$, spectrally sampled at $0.25 \mathrm{~cm}^{-1}$. IASI has a good radiometric performance, around $0.15 \mathrm{~K}$ (or around $\left.2 \times 10^{-6} \mathrm{~W} \mathrm{~cm}^{-2} \mathrm{sr}^{-1} / \mathrm{cm}^{-1}\right)$ in the $\mathrm{HCOOH}$ spectral range $\left(\sim 1105 \mathrm{~cm}^{-1}\right)$ for a reference blackbody at $280 \mathrm{~K}$ (Clerbaux et al., 2009).

Analysis of the mean of the normalized Jacobians (Fig. 2) over the spectral range used by IASI for the $\mathrm{HCOOH}$ retrievals $\left(1095-1114 \mathrm{~cm}^{-1}\right)$, for a set of representative geographical regions (see Fig. 1 and next section), shows that IASI is sensitive to tropospheric $\mathrm{HCOOH}$ between 1 and $6 \mathrm{~km}$. These Jacobians represent the sensitivity of IASI and the radiative transfer model to the abundance of $\mathrm{HCOOH}$ in a fixed atmosphere. This corresponds to the mean of the Jacobians simulated from the selected spectra over the studied regions.

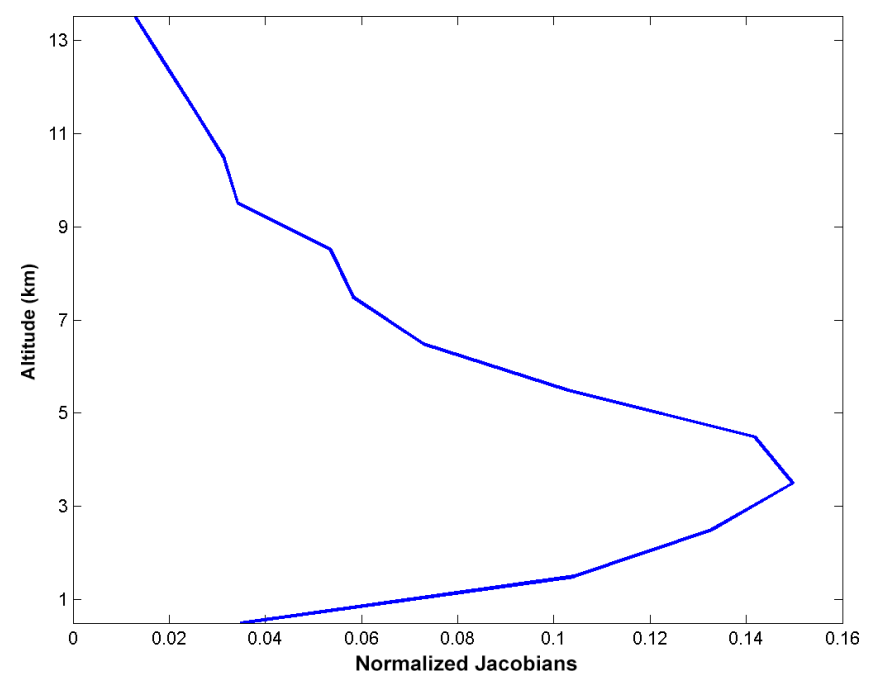

Figure 2. Mean normalized Jacobians of all retrieved spectra (over the seven selected regions) as a function of altitude.

\subsection{Retrieval approach}

Processing 7 years (2008-2014) of IASI data using an iterative method such as the OEM (Rodgers, 2000) is computationally demanding. Hence we have chosen a fast approach based on brightness temperature differences $\left(\Delta T_{\mathrm{b}}\right)$ between spectral channels with and without the signature of the target gas to extract information without performing a full retrieval. In a second step, the $\Delta T_{\mathrm{b}}$ were converted into total columns of $\mathrm{HCOOH}$ using conversion factors derived from a set of data retrieved by OEM. This approach was adapted from the previous works for other IASI weak absorbers, such as methanol (Razavi et al., 2011), sulfur dioxide (Clarisse et al., 2008), and ammonia (Van Damme et al., 2014).

In the current work, the main difference with the previous IASI HCOOH determination in Razavi et al. (2011) is the use of retrieved total columns over selected regions to determine conversion factors instead of the use of forward simulations. The OEM implemented in the line-by-line radiative transfer model Atmosphit (Coheur et al., 2005) has been used as in Razavi et al. (2011). In Razavi et al. (2011), the reason invoked for performing only forward simulations for $\mathrm{HCOOH}$ was the unstable character of the retrievals. With the retrieval settings chosen here, we relied on the retrieved columns since $82 \%$ of the selected spectra were successfully retrieved (Table 1) and the mean root mean square (RMS) between the observed and fitted spectra is about $2.5 \times 10^{-6} \mathrm{~W} \mathrm{~cm}^{-2} \mathrm{sr}^{-1} / \mathrm{cm}^{-1}$. This RMS value was close to the IASI-estimated radiometric noise.

The conversion factors allowing the calculation of total columns based on $\Delta T_{\mathrm{b}}$ values were determined by using the parameters from a linear regression, obtained by correlating $\Delta T_{\mathrm{b}}$ with $\mathrm{HCOOH}$ total columns based on the OEM retrieval. The spectroscopic parameters were from the $\mathrm{HI}$ - 
Table 2. Retrieval parameters used in this work.

\begin{tabular}{lllr}
\hline Parameters & Layers & A priori & Variability \\
\hline $\mathrm{H}_{2} \mathrm{O}$ & $0-10 \mathrm{~km}$ : five 2 km thick layers & EUMETSAT operational & $20 \%$ \\
& 10-20 km: two 5 km thick layers & level 2 & \\
$\mathrm{O}_{3}$ & total column & standard atmosphere & $20 \%$ \\
$\mathrm{NH}_{3}$ & ditto & standard atmosphere & $20 \%$ \\
$\mathrm{HCOOH}$ & ditto & Razavi et al. $(2011)$ & $350 \%$ \\
$\mathrm{CFC}-12$ & ditto & Coheur et al. (2003) & $20 \%$ \\
\hline
\end{tabular}

TRAN 2008 database (Rothman et al., 2009), using the set of $\mathrm{HCOOH}$ spectroscopic line parameters of Vander Auwera et al. (2007). The retrievals have been done with the same a priori profile as in Razavi et al. (2011) but with a loose constraint $(350 \%)$. The reference channels used for the calculation of $\Delta T_{\mathrm{b}}$ were chosen on both sides of the $\mathrm{HCOOH}$ channel $\left(1105 \mathrm{~cm}^{-1}\right)$, i.e., at 1103.0 and $1109.0 \mathrm{~cm}^{-1}$.

In the OEM-based retrieval, only cloud-free scenes (when the cloud coverage for the pixel is below $2 \%$ ) have been used. The total columns of interfering species in the studied spectral range, such as ozone, ammonia, and CFC-12, in addition to the partial columns of water vapor, were retrieved simultaneously. The details of the retrieval parameters are given in Table 2. The EUMETSAT L2 operational data were used, and daytime and nighttime data with a positive thermal contrast (TC) were taken into account. The TC was defined as the temperature difference between the surface and the air just above. Negative TC data were excluded as these were found to deteriorate the correlation $\Delta T_{\mathrm{b}}$-total column.

The OEM-based retrieval has been performed over seven geographical regions shown as blue boxes in Fig. 1. These include five source areas (in southern Africa, Northern Africa, Amazonia, Australia, Russia) and two remote areas (over the Atlantic and Pacific oceans). These seven regions are representative of different conditions: emission sources, remote areas, areas influenced by long-range transport, over land, and over sea. We have retrieved the 5 first days of each month in 2009 over the seven regions, allowing the characterization of the seasonal variation. The localization of each area and the number of retrieved spectra are given in Table 1.

From these retrievals, we derived a linear regression between the retrieved total columns and the $\Delta T_{\mathrm{b}}$, illustrated by Fig. 3a. A good correlation was found $(r=0.74)$ between both parameters. The density of the distribution is also given (Fig. 3b), showing a larger density of data between 0.3 and $0.6 \mathrm{~K}$ on the $\Delta T_{\mathrm{b}}$ axis and between 0.4 and $0.6 \times 10^{16}$ molec cm ${ }^{-2}$ for the total column. As in Razavi et al. (2011), this relationship was found to depend on the local TC conditions. This dependence is characterized by the color code showing the TC values in Fig. 3a. For example, a $\Delta T_{\mathrm{b}}$ equal to $0.5 \mathrm{~K}$ generally corresponds to a total column close to 0 at high TC, or around $2 \times 10^{16} \mathrm{molec}^{-2}$ at very low TC.

\subsection{Development of an updated IASI HCOOH data set}

\subsubsection{Reduction of the TC dependence}

To account for the TC dependence in the $\Delta T_{\mathrm{b}}$-total column relationship as shown in Fig. 3a, we have performed forward simulations with different TCs, using the observation made in the regions and periods listed in Table 1 . We artificially modified the surface temperature for each atmospheric profile by $\pm 5 \mathrm{~K}$. In total, three $\mathrm{TC}$ conditions were simulated: $\mathrm{TC}_{\mathrm{ref}}, \mathrm{TC}_{\mathrm{ref}}+5 \mathrm{~K}$, and $\mathrm{TC}_{\mathrm{ref}}-5 \mathrm{~K}$. These simulations were performed with the a priori as initial total column. In total, 13155 spectra were simulated. The linear regression between TC and $\Delta T_{\mathrm{b}}$ is illustrated in Fig. 4a. A fair correlation was found, with $r$ equal to 0.6. Based on this linear regression, a corrected $\Delta T_{\mathrm{b}}\left(\Delta T_{\mathrm{bTC}}\right)$ was defined using Eq. (1):

$\Delta T_{\mathrm{bTC}}=\Delta T_{\mathrm{b}}-\left(\mathrm{TC} \times a_{1}+a_{2}\right)$,

with $a_{1}=0.0138$ and $a_{2}=0.3502$. These $\Delta T_{\mathrm{bTC}}$ still presented a high correlation with the OEM-based total columns $(r=0.75)$ and the TC dependence disappeared, as shown in Fig. $4 \mathrm{~b}$. We then deduced a relationship between the total column and the measured $\Delta T_{\mathrm{b}}$ :

$x=b_{1} \times \Delta T_{\mathrm{bTC}}+b_{2}$,

where $x$ is the total column in $10^{16}$ molec $\mathrm{cm}^{-2}, b_{1}=$ 1.5713 , and $b_{2}=0.6792$.

Note that this conversion could lead to negative total columns. If we eliminated all the negative values and kept only all the positive values, we would introduce an artificial bias in the average. For comparisons with zonal or temporal averages, the negative total columns were included in the average. However, when the average was found to be negative, it was filtered out.

\subsubsection{Error estimation}

This technique has a low computational cost but the drawbacks of the method are the difficulty to characterize the retrieval in terms of vertical sensitivity (averaging kernels not available) and the lack of an error budget.

The total error of the $\Delta T_{\mathrm{b}}$ approach can be described by three terms: (1) the instrumental error, (2) the error caused 

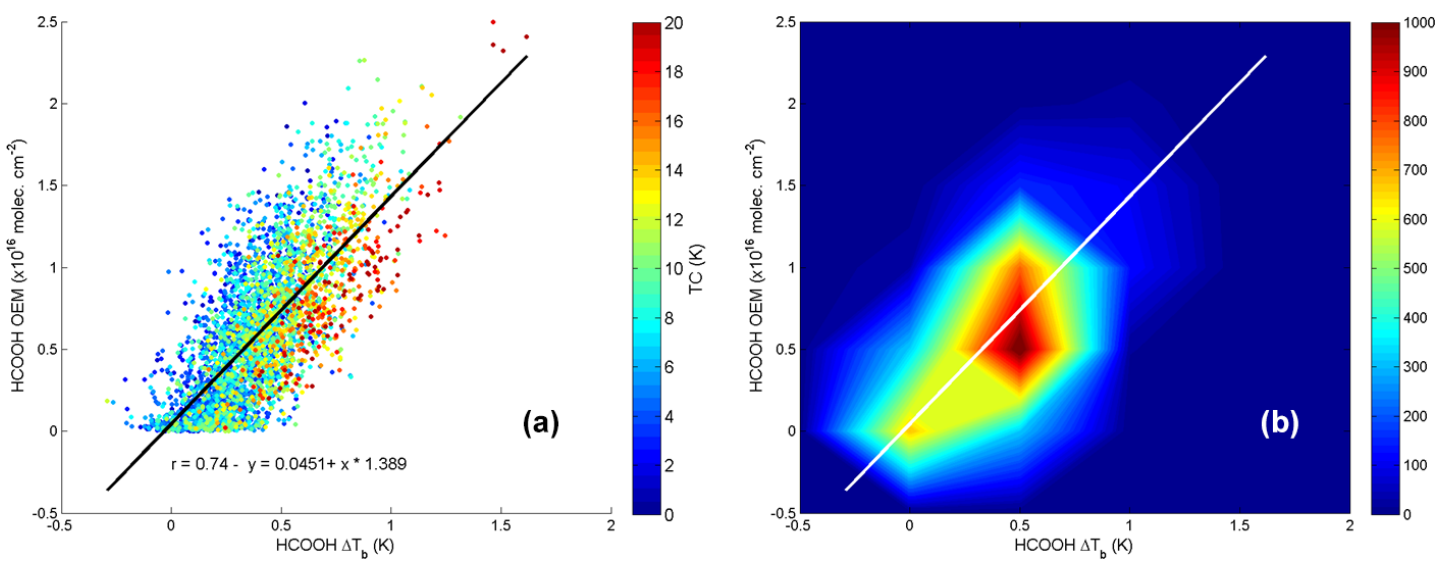

Figure 3. (a) Scatter plot of all the retrieved total columns using the optimal estimation method and the corresponding $\mathrm{HCOOH} \Delta T_{\mathrm{b}}$. The black line corresponds to the linear regression. Each data point is colored based on its thermal contrast value. (b) Distribution of points density from the scatter plot. The number of points is highlighted with the color scale. The linear regression is also reported by a white line.
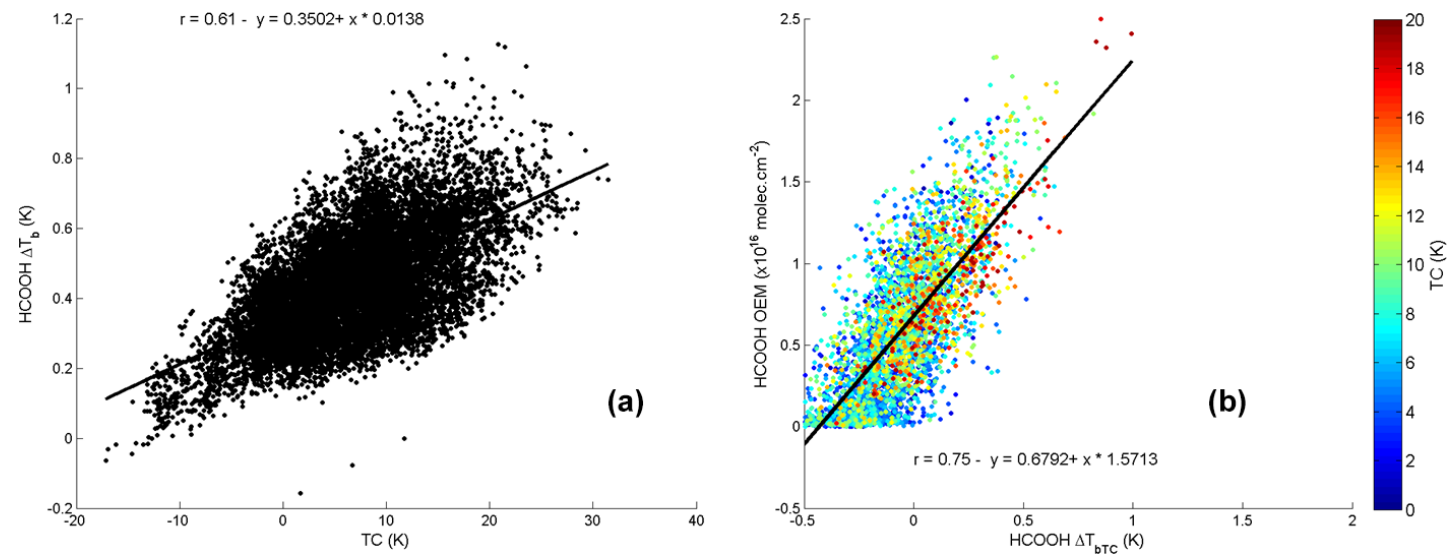

Figure 4. (a) Scatter plot of the simulated $\Delta T_{\mathrm{b}}$ and the TC for one fixed HCOOH total column $\left(0.6 \times 10^{16} \mathrm{molec}^{-2}\right)$. (b) Scatter plot between the $\mathrm{HCOOH}$ retrieved total columns using the optimal estimation method and the corrected $\mathrm{HCOOH} \Delta T_{\mathrm{bTC}} \Delta T_{\mathrm{bTC}}$ corresponds to the $\mathrm{HCOOH} \Delta T_{\mathrm{b}}$ taking account the TC dependence, given by the equation in panel (a). Each data point is colored based on its thermal contrast value as in Fig. 3a.

by the conversion from $\Delta T_{\mathrm{b}}$ to total column, and (3) the error originating in the OEM-based retrieval. To provide an estimate of the algorithm error, simulations were performed for the data set over the seven regions, using six initial total columns, i.e., by perturbing the a priori $(-50 \%$, the reference a priori, $+50,+100,+200,+350 \%)$. In total, 26310 forward simulations were used. In the simulations, the temperature profile used was from EUMETSAT operational level 2.

A Gaussian distributed random noise (with $\sigma=0.15 \mathrm{~K}$, corresponding to the noise in the studied spectral range) was added to the $T_{\mathrm{b}}$ channels used for the $\Delta T_{\mathrm{b}}$ calculation from the simulated spectra. Then the conversion formula (Eq. 2) was applied to the calculated $\Delta T_{\mathrm{b}}$.

Figure 5 shows the histogram of the relative difference (RD) between the calculated total columns and the true total columns used as input in the forward simulations. The $\mathrm{RD}$ was defined as the difference between the calculated to- tal columns and the true total columns, divided by the latter. Positive RDs imply that the calculated total column is higher than the true column. This histogram presents a mean of $\sim 1.6 \%$ and a standard deviation around $69 \%$. Note that these results agree with those from Razavi et al. (2011), who found a mean RD equal to $-0.8 \%$ and a standard deviation of $60 \%$. The RD was not impacted by the TC or the $\mathrm{H}_{2} \mathrm{O}$ profile but it depended on the $\mathrm{HCOOH}$ total column. Figure $6 \mathrm{a}$ shows the dependence of the mean RD on the $\mathrm{HCOOH}$ total column used as input to the forward simulation. Large positive RDs (up to $78 \%$ ) were found for low total columns whereas negative RDs prevailed for large $\mathrm{HCOOH}$ columns (lower than $35 \%$ ). In other words, the retrieval based on brightness temperature differences tends to overestimate the low values of the true columns and to underestimate the high values. 


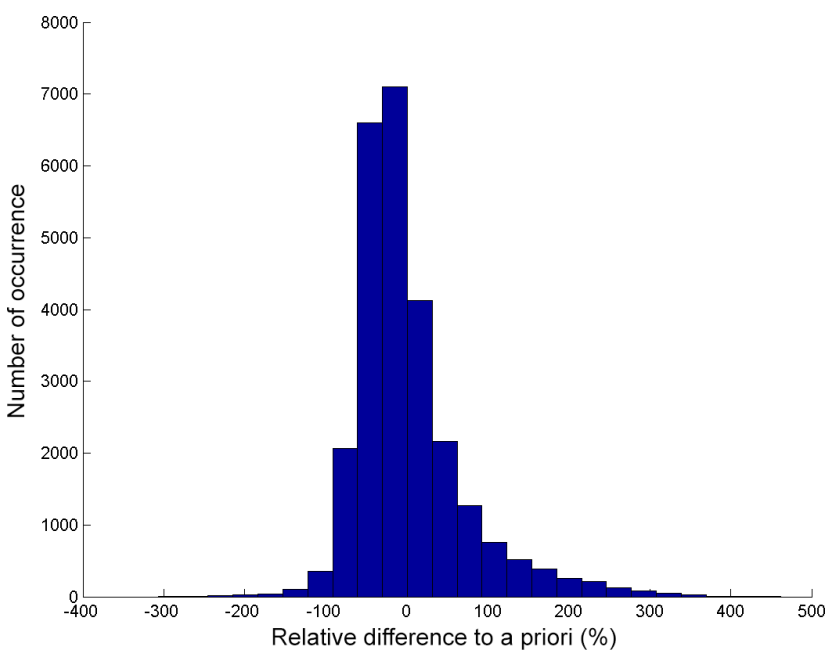

Figure 5. Histogram of the relative differences between the calculated total columns (derived from the $\Delta T_{\mathrm{b}}$ conversion) and the a priori total columns (used as input in the forward simulations). The a priori total columns are defined as the reference.

Considering the detection threshold defined as $2 \sigma$ on the $\Delta T_{\mathrm{b}}(=0.30 \mathrm{~K})$, an indicative total column detection threshold was calculated using our conversion factors. To do so, forward simulations were performed for different total columns and TC. The result is illustrated in Fig. $6 \mathrm{~b}$ and this shows that for the less favorable $\mathrm{TC}$ condition $(\mathrm{TC}=0 \mathrm{~K})$ the detection limit of $\mathrm{HCOOH}$ is close to $0.6 \times 10^{16}$ molec $\mathrm{cm}^{-2}$ $\left(0.4 \times 10^{16}\right.$ molec $\mathrm{cm}^{-2}$ for $\left.\sigma\right)$. This detection limit is improved with higher TC.

\section{Analysis of the data set}

\subsection{Global distributions}

Mean $\mathrm{HCOOH}$ global distributions (averaged on a $0.5^{\circ} \times 0.5^{\circ}$ grid) from IASI for the 2008-2014 period are presented in Fig. 7 and compared with columns obtained using the retrieval method of Razavi et al. (2011). Note that Razavi et al. (2011) retrieved only total columns over land. Except over Indonesia, lower values are observed over the source regions with the updated data set. The previous section shows that large positive RDs are expected for very low true columns. Even if the columns from Razavi et al. (2011) are not the true columns, this could explain why the total columns for this study are higher over remote areas (e.g., deserts) than those obtained using the methodology described by Razavi et al. (2011). It is also important to note that in Razavi et al. (2011) only averaged data in a $0.5^{\circ} \times 0.5^{\circ}$ grid with TC higher than $5 \mathrm{~K}$ were considered. This implies that only data with a strong signal were used, probably overestimating the threshold of the $\Delta T_{\mathrm{b}}$ and thus also the retrieved columns.
Yearly global distributions between 2008 and 2014 with the updated data set are also presented in Fig. 8 (on a $1^{\circ} \times 1^{\circ}$ grid).

These distributions highlight well the recurring source regions detected by IASI such as equatorial Africa, northern Australia, Amazonia, and India, as well as the longrange transport such as over the Atlantic Ocean from Africa. The long-range transport over oceans (Atlantic, Indian, and Pacific) was not investigated in Razavi et al. (2011). The retrieved columns over the Atlantic Ocean are consistent with the Fourier transform infrared spectroscopy (FTIR) data from ship cruises reported in the study of Paulot et al. (2011). They showed a gradient of columns from the poles to the Equator, with the highest values between 0 and $10^{\circ} \mathrm{N}$, but with large variability, as the maximum was $3.5 \times 10^{16}$ molec $\mathrm{cm}^{-2}$ but the monthly mean in this region was only $0.5 \times 10^{16}$ molec $\mathrm{cm}^{-2}$.

Several hotspots and distributions are detected and are numbered from (1) to (10) in Fig. 8.

A particularly striking feature is the large hotspot over Russia (close to Moscow) in 2010 as documented by R'Honi et al. (2013) due to intense forest fires during the summer and also in 2012 over Siberia (see label 1). The current data set presents a mean total column twice lower $\left(2.0 \times 10^{16}\right.$ molec cm $\left.^{-2}\right)$ than the mean derived using the conversion from Razavi et al. (2011) $\left(4.2 \times 10^{16}\right.$ molec cm $\left.^{-2}\right)$, within the emission area $\left(50-55^{\circ} \mathrm{N}, 30-70^{\circ} \mathrm{E}\right)$, on $27 \mathrm{July}-$ 27 August 2010, in agreement with the conclusions from R'Honi et al. (2013). Over Russia, other large columns were also found over Sakha Republic and over Khabarovsk Krai in 2008 and 2012 (see label 2). It is also worth noting that the North American boreal emissions around the Hudson Bay were larger between 2008 and 2010 compared to other years (see label 3). Over North America, and especially the USA, we observe lower columns over Louisiana and Texas in 2008 and in 2014 compared to the other years (see label 4); while larger total columns were measured over northern Australia between 2012 and 2014, in comparison to the period from 2008 to 2010 (see label 5).

The monthly means over the 7 years are also presented with an animation (Fig. S1) in the Supplement. As already observed over eastern Russia with label (2), in June 2010 and 2012, there were large concentrations, close to Khabarovsk Krai, compared to the other years in this region. Whereas intense fires were detected in June 2012 in this region, this was not the case in June 2010 (see maps on http://lance-modis. eosdis.nasa.gov/cgi-bin/imagery/firemaps.cgi). The absence of forest fires and the lack of hotspots in the biogenic emission inventory (Fig. 1) in this region points to the presence of an unidentified source, possibly of biogenic origin.

Large columns were similarly retrieved over a large region encompassing Laos, Thailand, and Myanmar in April 2010, 2012, 2013, and 2014 (see label 6). It matches well with the locations of fire hotspots detected by MODIS. 

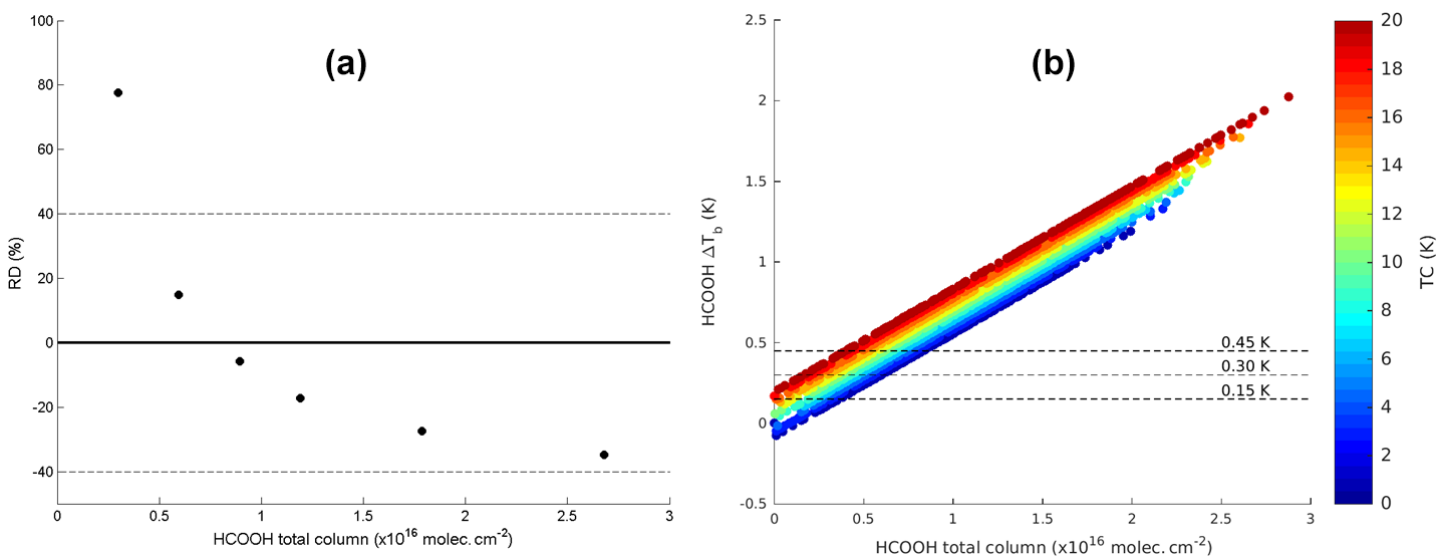

Figure 6. (a) Variation of the mean relative difference between the total columns derived from the $\Delta T_{\mathrm{b}}$ conversion and the a priori total columns (used as input in the forward simulations) according to the a priori used. The black solid line corresponds to a relative difference equal to 0 and the dashed black lines to $\pm 40 \%$. (b) Variation of the simulated $\Delta T_{\mathrm{b}}$ for different HCOOH total columns and TC. The dashed black lines correspond to a $\Delta T_{\mathrm{b}}$ equal to $0.15,0.30$, and $0.45 \mathrm{~K} ; 0.15 \mathrm{~K}$ corresponds to the IASI radiometric noise in the HCOOH spectral range (see Sect. 2.1).
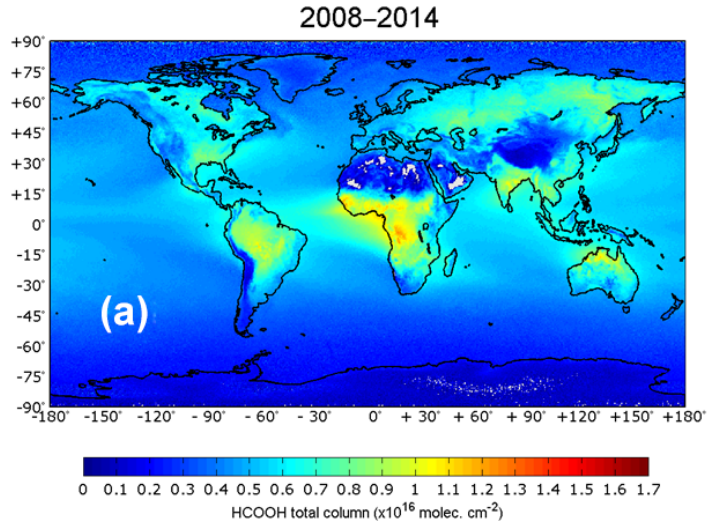

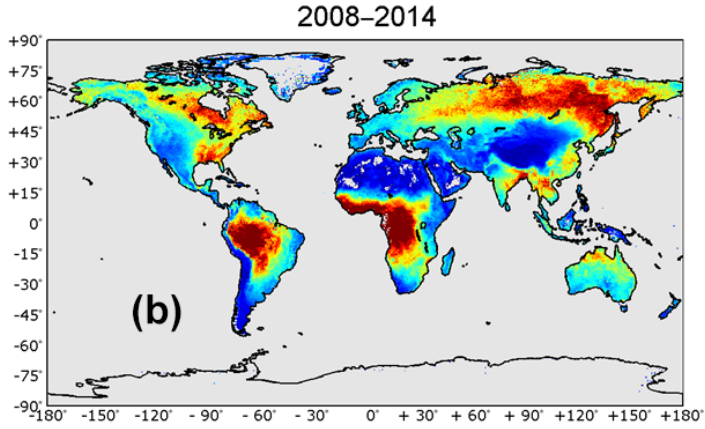

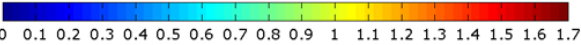
$\mathrm{HCOOH}$ total column $\left(x 10^{16} \mathrm{molec}_{\mathrm{cm}} \mathrm{cm}^{-2}\right)$ - Razavi et al. (2011)

2008-2014

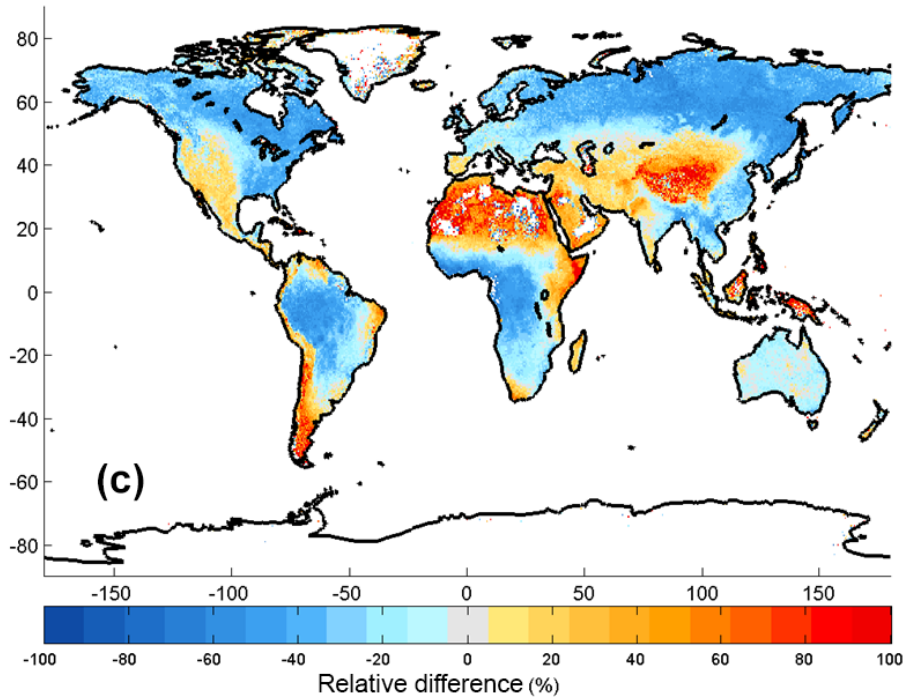

Figure 7. Mean $\mathrm{HCOOH}$ global distribution between 2008 and 2014, derived using the IASI radiance observations on a $0.5^{\circ} \times 0.5^{\circ}$ grid with the retrieval from this work (a), using the methodology described by Razavi et al. (2011) (b), and the relative difference between both distributions in percent (c). The relative difference is defined as $\left(\mathrm{HCOOH}_{\text {this work }}-\mathrm{HCOOH}_{\text {Razavi et al. (2011) }}\right) / \mathrm{HCOOH}_{\mathrm{Razavi}}$ et al. (2011) . 

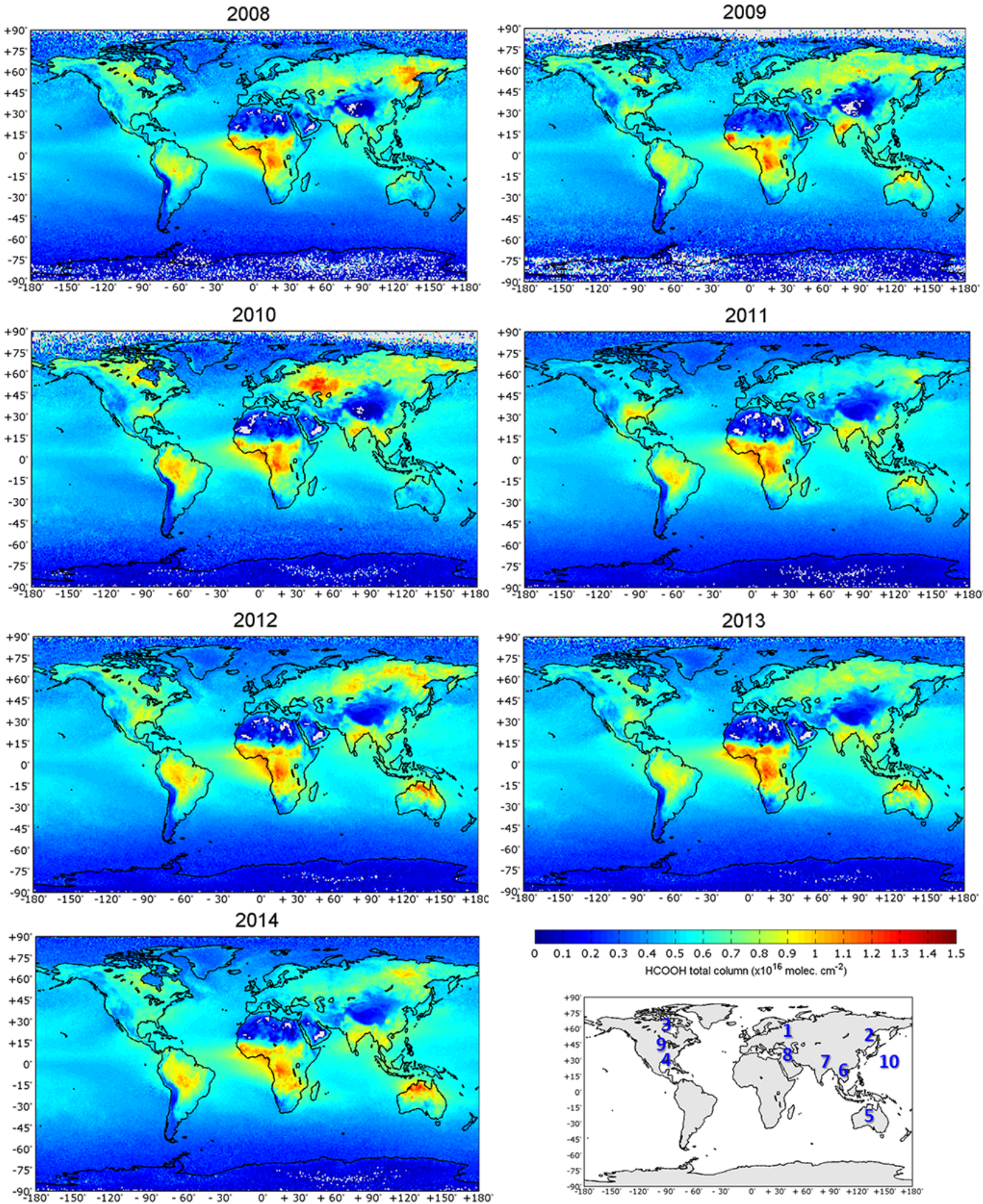

Figure 8. Annual $\mathrm{HCOOH}$ global distribution from 2008 to 2014 , derived using the IASI radiance observations on a $1^{\circ} \times 1^{\circ}$ grid. Different sources or distributions described in the text are numbered in blue on the bottom-right map. 
Over India, the largest total columns are observed from March to June probably due to biomass burning (see label 7). Indeed, those emissions present a marked seasonal variation with a maximum in March-May according to the GFED3 inventory (van der Werf et al., 2010), with 50, 22, and $11 \%$ of annual emissions occurring in March, April, and May, respectively.

Larger total columns were retrieved in August 2010 along the Euphrates River compared to the other years (see label 8).

The monthly distributions also highlight hotspots over the USA, besides those shown in the annual distributions (see label 9). In summer 2011, large signatures over the USA were not confined to coastal regions; high total columns were also detected in the Midwestern USA such as over Kansas, Mississippi, Missouri, or Oklahoma. These states are flagged as biogenic emission regions of VOCs by Millet et al. (2015), acting as secondary source of $\mathrm{HCOOH}$. In July 2012, the emissions over the USA were mostly confined to the eastern part.

The Asian $\mathrm{HCOOH}$ outflow is well captured over the western Pacific (see label 10). The range of values of the IASI total columns, from 2008 to 2014, broadly agrees with our estimation of total columns using the measurements from the aircraft PEM-West-B campaign conducted in February-March 1994 (Talbot et al., 1997a, b) over a large region covering the latitudes $0-60^{\circ} \mathrm{N}$ and the longitudes $110-180^{\circ} \mathrm{E}$. Indeed, measured $\mathrm{HCOOH}$ mixing ratio profiles during the campaign mostly ranged around 100$150 \mathrm{pptv}$ from the boundary layer to about $12 \mathrm{~km}$ altitude, with peak values of up to $4 \mathrm{ppbv}$ in fresh $(<2$ days $)$ plumes originating in China. Using these profiles, we estimated that this corresponded approximately to columns ranging from 0.2 to $0.9 \times 10^{16}$ molec $\mathrm{cm}^{-2}$ while the IASI mean column is around $0.55 \times 10^{16}$ molec $\mathrm{cm}^{-2}$. Over the remote Pacific, the IASI total columns, for the studied period, are larger than measured during the aircraft PEM-Tropics-A campaign in August-December 1996 (e.g., Talbot et al., 1999). They measured mixing ratios of the order of $20-40 \mathrm{ppbv}$ in the boundary layer and $50-100 \mathrm{pptv}$ in the free troposphere, corresponding to estimated total columns of $0.1-$ $0.2 \times 10^{16} \mathrm{molec} \mathrm{cm}^{-2}$. This overestimation is in agreement with the error budget from Fig. 6 .

Overall, these monthly means highlight the seasonal variation of the $\mathrm{HCOOH}$ distribution around the world. The animation reveals clear variations in the $\mathrm{HCOOH}$ distribution due to the seasonality of biomass burning and vegetation growth. This is shown well with the large total columns observed during September and October 2008, 2012, and 2014 in the Southern Hemisphere (over Amazonia, Africa, and Australia). In 2010, the same features were noted except for Australia.

\subsection{Comparison with ground-based FTIR measurements}

The IASI HCOOH retrieved columns in this work have been compared with ground-based FTIR measurements. This comparison was done without smoothing the data since the averaging kernels (AKs) were not provided by our retrieval method. This comparison is presented at four sites: Jungfraujoch $\left(46.55^{\circ} \mathrm{N}, 7.98^{\circ} \mathrm{E}\right)$ in Switzerland, Wollongong in Australia $\left(34.41^{\circ} \mathrm{S}, 150.88^{\circ} \mathrm{E}\right)$, and Saint-Denis $\left(20.88^{\circ} \mathrm{S}\right.$, $\left.55.45^{\circ} \mathrm{E}\right)$ and Maido $\left(21.07^{\circ} \mathrm{S}, 55.39^{\circ} \mathrm{E}\right)$ at La Réunion (Fig. 9). The current retrieved columns have also been evaluated with those using the methodology from Razavi et al. (2011) over the same sites (Fig. 10).

A complete description of the FTIR instruments and the retrieved $\mathrm{HCOOH}$ data can be found in Zander et al. (2010), Paton-Walsh et al. (2005), and Vigouroux et al. (2012) for the Jungfraujoch, Wollongong, and Saint-Denis stations, respectively. For the Jungfraujoch, spectra were typically recorded at spectral resolutions of 0.004 and $0.006 \mathrm{~cm}^{-1}$. For the present subset, a mean signal-to-noise ratio (SNR) of 895 was computed, with 10th and 90th percentiles of 525 and 1525 , respectively. A uniform scaling of the $\mathrm{HCOOH}$ a priori was performed, and no information was available regarding the sensitivity of the retrieval with altitude. For Wollongong, the spectral resolution was $0.004 \mathrm{~cm}^{-1}$ and the SNR was around 1000-2000. Over La Réunion, the $\mathrm{HCOOH}$ retrieval parameters were the same for Saint-Denis and for the more recent data at the Maïdo station. The spectral resolution of La Réunion spectra was 0.007 or $0.011 \mathrm{~cm}^{-1}$, depending on the time of the measurement. The SNR was about 1000 2000 depending on the spectra.

The current IASI retrieved columns were also compared with a set of columns retrieved by OEM around the sites. For each OEM-based retrieved column, the corresponding column using the conversion factors was calculated, showing that the current data set and the OEM-based retrieval are in agreement (correlation ranging from 0.7 to 0.8 , with an underestimation of the columns calculated with the conversion factors between 6 and $15 \%$ ) (Fig. S2). It is also worth noting that similar biases were found between the columns retrieved by OEM around the ground-based locations and the FTIR columns as between the columns retrieved in this work and the FTIR ones (Table S1).

Averaging kernels were also unavailable for the FTIR measurements performed at Jungfraujoch (extended from Zander et al., 2010) and at Wollongong (Paton-Walsh et al., 2005). The measurements at Saint-Denis and Maido reached a maximum sensitivity between about 3 and $12 \mathrm{~km}$ as described in Vigouroux et al. (2012) and shown in Fig. 11. The AKs indicate the vertical sensitivity of the retrieval. The Jacobians express the sensitivity of the radiative transfer model and the IASI instrument (through its instrumental function) to the variation of $\mathrm{HCOOH}$ in the atmosphere. Both functions then give a good indication of the vertical sensitivity 

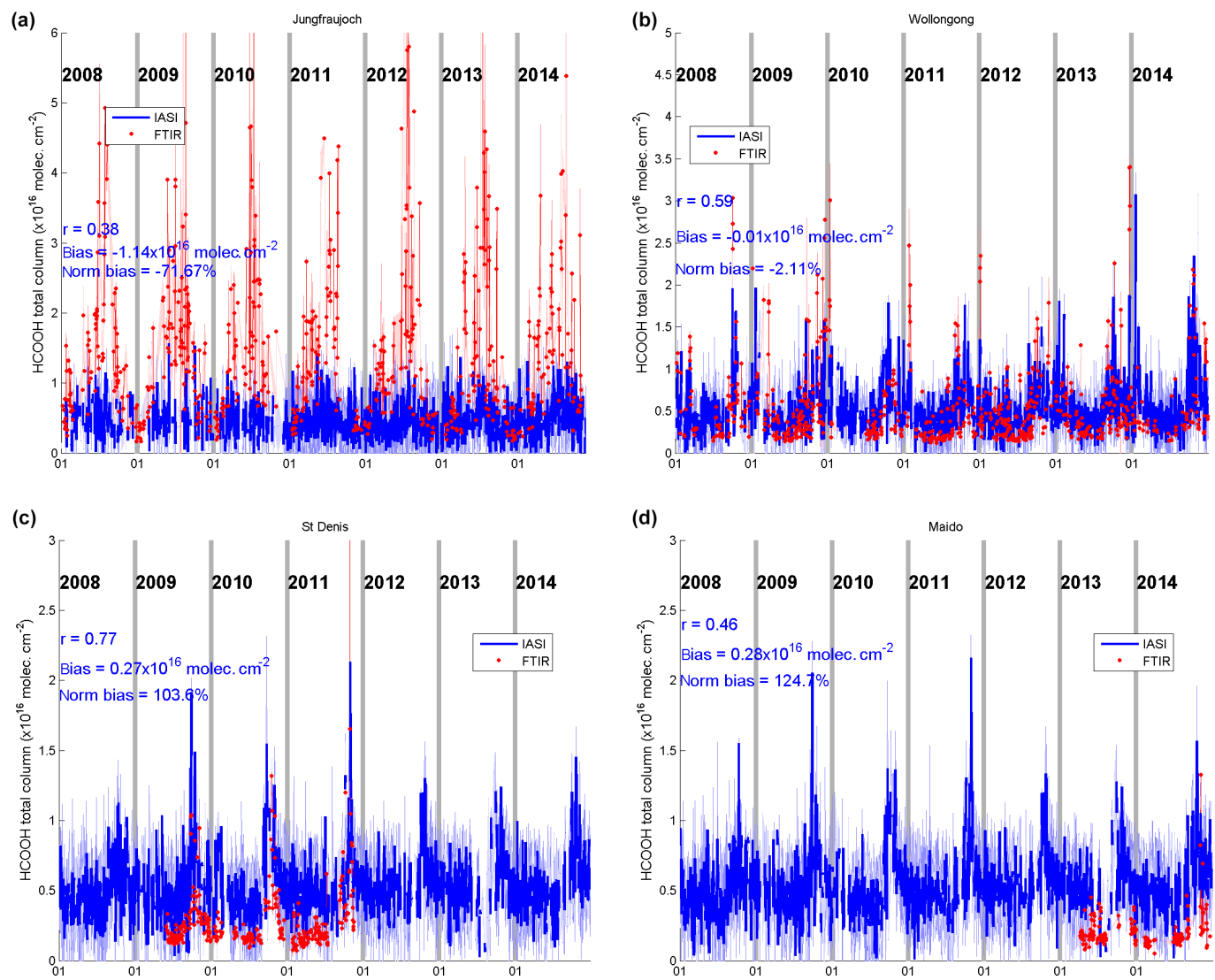

Figure 9. Time series of $\mathrm{HCOOH}$ daily means over Jungfraujoch (a), Wollongong (b), Saint-Denis (c), and Maido (d) between 2008 and 2014 for IASI (blue) and the ground-based FTIR (red) measurements. The IASI data are collocated at $\pm 0.5^{\circ}$ around the site location. The correlation coefficient, the mean bias, and the normalized mean bias for all years are given in blue font on each plot. The blue shade error bar corresponds to the standard deviation on the IASI daily means. The altitude of the stations is $3.6 \mathrm{~km}$ for Jungfraujoch, $20 \mathrm{~m}$ for Wollongong, $50 \mathrm{~m}$ for Saint-Denis, and $2.2 \mathrm{~km}$ for Maido.

for each data set. These AKs and the Jacobians show that FTIR and IASI were both mostly sensitive to the free troposphere but that the FTIR measurements presented a broader vertical sensitivity, reaching higher altitudes than IASI.

A difficulty in comparisons of satellite columns with ground-based measurements over mountain sites like Jungfraujoch over the Swiss Alps (3.6 km altitude) or Maido at La Réunion ( $2.2 \mathrm{~km}$ altitude) is the difference of altitude between the FTIR sites and the co-located IASI ground pixel height. To account for the altitude dependence, both the IASI and the FTIR total columns were normalized to the sea level altitude using

$C_{\text {corrected }}=C \times \exp (H / 7.4)$,

where $H$ represents the ground measurement height (in $\mathrm{km}$ ) and $C$ is the total column (in $10^{16} \mathrm{molec} \mathrm{cm}^{-2}$ ). This simplified formula is a variation of the hypsometric equation (Wallace and Hobbs, 1977). This normalization relies on the assumption that the $\mathrm{HCOOH}$ mixing ratio is constant as a function of altitude. Although crude, this procedure improved the comparisons.
The time series of the IASI and FTIR columns over the selected sites are shown in Fig. 9. The comparison used IASI data collocated within $0.5^{\circ}$ of the site location in both latitude and longitude. To keep enough IASI data to compare, daily averages were used. A more stringent criterion of $\pm 2 \mathrm{~h}$ was tested but provided similar results, except over Maido where the correlation increased to 0.6 without improvement of the bias. The advantage of this daily average is the possibility to derive the seasonal variation over each site. Over all sites, the broad patterns of seasonal and interannual variations were similarly captured by IASI and the ground-based FTIR.

The comparison between the ground-based measurements and the total column derived from the IASI spectra may be affected by sampling differences associated, e.g., with cloudiness. IASI may be able to measure through clear skies in the vicinity of the station when the FTIR data are not available due to localized cloud. Moreover, despite the use of strict co-location criteria (spatial and temporal), most mismatches in peak values could be a result of mismatches in the spatial and temporal scales of the measurements being compared. 

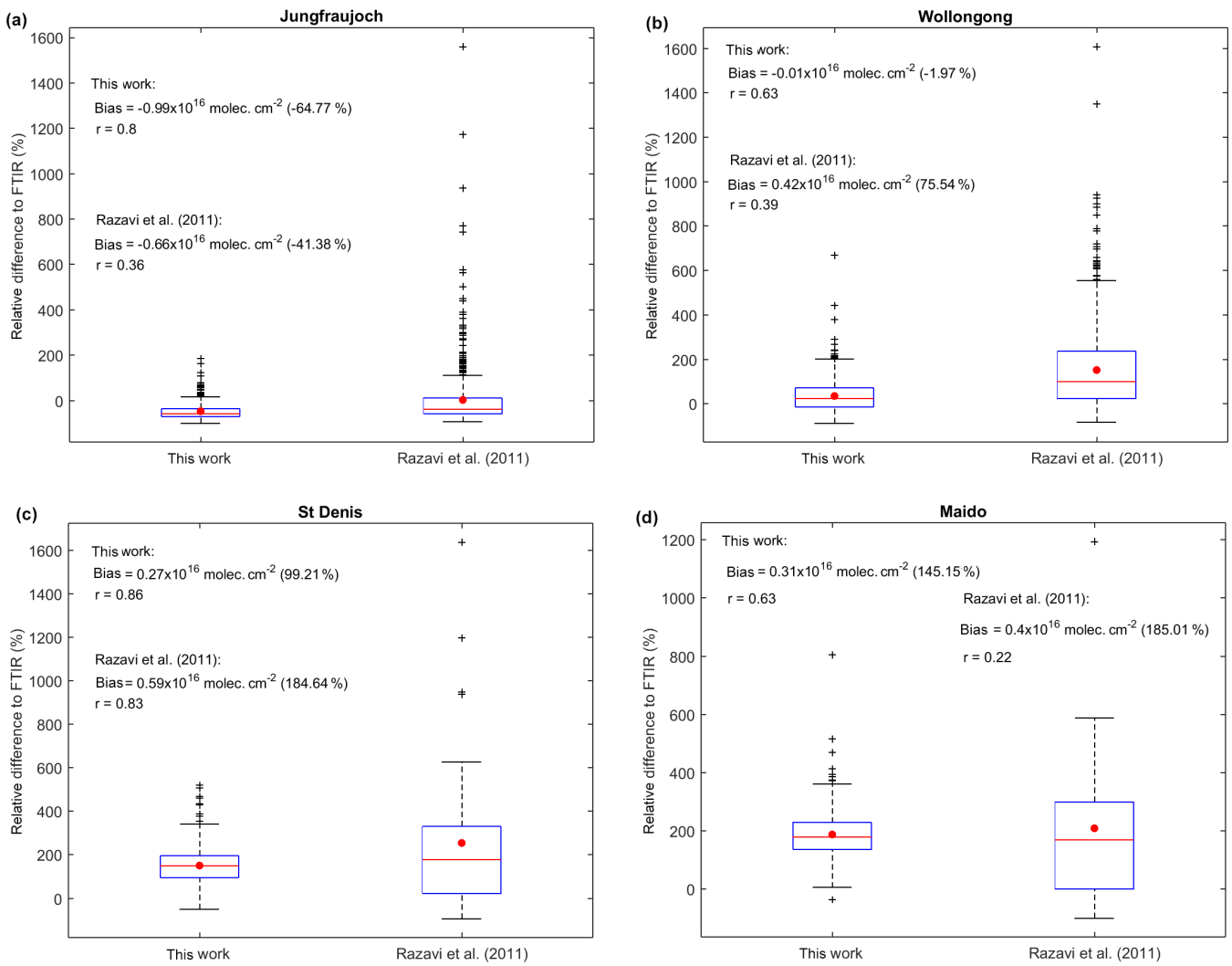

Figure 10. Box and whisker plots showing mean (red central circle), median (red central line), and 25th and 75th percentile (blue box edges) of the relative difference between the $\mathrm{HCOOH}$ derived using the IASI radiance observations from this work or using the conversion from Razavi et al. (2011) and the FTIR measurements for each station: Jungfraujoch, Wollongong, Saint-Denis, and Maido. The whiskers encompass values from 25 th $-1.5 \times(75$ th -25 th $)$ to the 75 th $+1.5 \times(75$ th -25 th $)$. This range covers more than $99 \%$ of a normally distributed data set. The outliers are represented individually by black crosses. For this comparison, the IASI data are collocated at $\pm 4^{\circ}$ around the site location. The mean bias, the normalized mean bias (in parentheses), and the correlation coefficient are given for both methods.

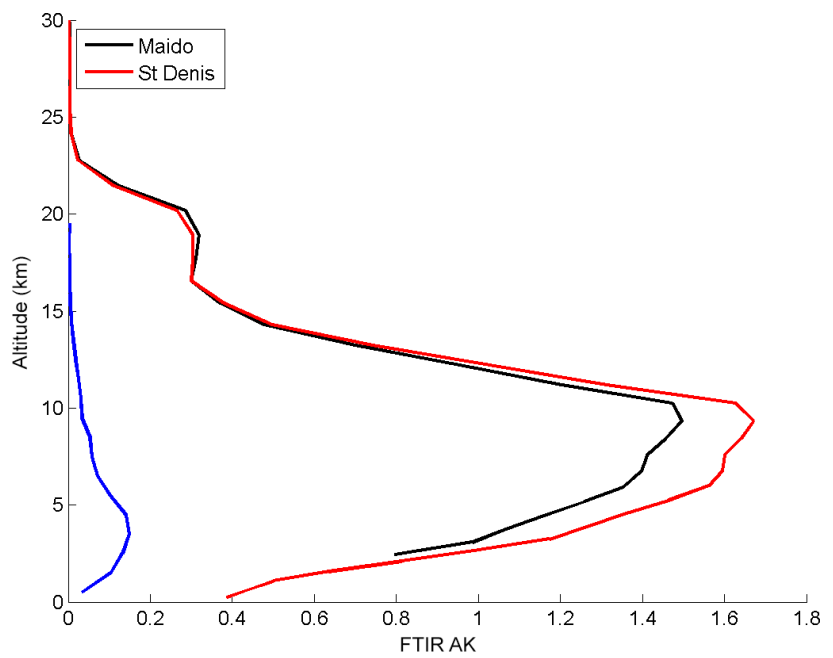

Figure 11. Mean total column AK for the FTIR ground-based measurements over Maido (black) and Saint-Denis (red) at La Réunion. Both stations are shown by green stars in Fig. 1. Both FTIR stations have a degree of freedom for signal close to 1 . As reminder, the mean normalized Jacobian from Fig. 2 is plotted in blue.
The correlation coefficients and the biases between FTIR and IASI are also provided for each year in Table 3. Over Jungfraujoch (Fig. 9), large total columns were measured by the ground-based instrument during the spring and the summer for each year. These large values were not captured by IASI data, causing a large bias of $1.14 \times 10^{16}$ molec cm $^{-2}$ on average. The comparison at Jungfraujoch presents the lowest correlation coefficient among the four stations. This might be caused to some extent by the error associated with the normalization to the sea level, which is largest at the high altitude of the Jungfraujoch.

The seasonal cycle obtained from IASI agrees well with FTIR data over both sites at La Réunion (correlation coefficient $r=0.77$ at St-Denis, up to 0.85 in 2011; see Table 3 ) but the columns from the IASI retrieval show a large positive bias at both sites $(>100 \%)$. The overestimation by IASI is especially large for background columns, i.e., between February and July, when FTIR columns are of the order of $0.15 \times 10^{16}$ molec $\mathrm{cm}^{-2}$. This increase of the bias for lower values of the true column is qualitatively consistent with the dependence of the error associated with the con- 
Table 3. Correlation coefficient (in italics), mean bias in $10^{16}$ molec $\mathrm{cm}^{-2}$, and normalized mean bias (square brackets) in percent between the daily FTIR measurements and the IASI co-located data. The IASI data were chosen at $\pm 0.5^{\circ}$ around the site location. The number of coincidence days is given in parentheses.

\begin{tabular}{|c|c|c|c|c|c|c|c|}
\hline FTIR station & 2008 & 2009 & 2010 & 2011 & 2012 & 2013 & 2014 \\
\hline \multirow[t]{2}{*}{ Jungfraujoch } & $0.33-1.10$ & $0.06-1.21$ & $0.23-1.26$ & $0.49-0.99$ & $0.47-1.15$ & $0.54-1.24$ & $0.43-1.06$ \\
\hline & {$[-71.8](57)$} & {$[-72.9](53)$} & {$[-73.7](69)$} & {$[-69.0](91)$} & {$[-72.4](97)$} & {$[-71.4](106)$} & {$[-71.1](78)$} \\
\hline \multirow[t]{2}{*}{ Wollongong } & $0.77-0.07$ & 0.160 .01 & 0.560 .03 & $0.60-0.02$ & $0.63-0.01$ & $0.69-0.03$ & 0.570 \\
\hline & {$[-11.2](50)$} & [2.9] (79) & [6.1] (44) & {$[-3.5](96)$} & {$[-1.1](124)$} & {$[-5.1](106)$} & [0.6] (56) \\
\hline Saint-Denis & - & 0.690 .28 & 0.750 .24 & 0.850 .27 & - & - & - \\
\hline (La Réunion) & & [110.1] (82) & {$[100.1](72)$} & [100.6] (97) & & & \\
\hline $\begin{array}{l}\text { Maïdo } \\
\text { (La Réunion) }\end{array}$ & - & - & - & - & - & $\begin{array}{r}0.350 .28 \\
{[131.2](60)}\end{array}$ & $\begin{array}{r}0.530 .28 \\
{[117.7](49)}\end{array}$ \\
\hline
\end{tabular}

version from brightness temperatures on the magnitude of the true column and especially for lower TC (Fig. 6): the expected error is lower than $20 \%$ for columns ranging between 0.5 and $1 \times 10^{16}$ molec $\mathrm{cm}^{-2}$ and close to $80 \%$ for columns lower than $0.3 \times 10^{16}$ molec cm $\mathrm{cm}^{-2}$. In addition, the difference in the altitude range of the vertical sensitivity between IASI and the FTIR could also contribute to the biases at Saint-Denis and Maido. Regarding the time series at $\mathrm{La}$ Réunion, it is worth noting that large columns measured in October 2010 and 2011 over Saint-Denis, corresponding to enriched plumes from Africa, are seen in the spatial distributions (Fig. S1).

At Wollongong, IASI and ground-based FTIR background levels are in broad agreement. The correlation is highest in 2008. The peaks in the $\mathrm{HCOOH}$ columns in October 2012, 2013 and in November 2014 observed by both instruments are also seen in the distributions in Fig. S1. As in the case of La Réunion data, a larger positive bias is found when the FTIR total columns are low $\left(<0.5 \times 10^{16}\right.$ molec $\left.\mathrm{cm}^{-2}\right)$.

The FTIR measurements were also used to evaluate the current $\mathrm{HCOOH}$ columns with those using the conversion from Razavi et al. (2011) (Fig. 10). The colocation criteria have been enlarged to $\pm 4^{\circ}$ as used in the evaluation shown in Stavrakou et al. (2012). The criterion was enlarged since the number of available data from Razavi et al. (2011) around the sites was less important than for the current data set. Figure 10 shows the distribution of the RDs with the FTIR measurements for both methodologies. It provides information about the bias, the normalized bias, and the correlation coefficient. At all sites, the distribution is more spread out with the conversion from Razavi et al. (2011). The correlation coefficient is largely improved with the updated data set, except over Saint-Denis where it is similar. The bias is also significantly reduced with the updated data set except over Jungfraujoch. This difference over Jungfraujoch is coherent with the previous comparison (Fig. 9) since the updated data set is underestimated compared to the FTIR measurements.

Overall, the current data set presents higher correlation and lower bias than the columns from Razavi et al. (2011).

\subsection{Comparison with IMAGESv2}

The IMAGESv2 global CTM runs at $2^{\circ}$ resolution in latitude and $2.5^{\circ}$ resolution in longitude. The model is resolved at 40 vertical levels, from the surface up to $44 \mathrm{hPa}$ (Stavrakou et al., 2011). The biogenic emissions of isoprene (believed to be the most important precursor of $\mathrm{HCOOH}$ ) were obtained from MEGAN-MOHYCAN (Stavrakou et al., 2014). The vegetation fire emissions were from GFEDv3 (van der Werf et al., 2010). This data set distinguished emissions from savanna, woodland, forest fires, agricultural waste burning, peatlands, deforestation, and degradation fires. Anthropogenic emissions were constructed from a mix of inventories: REASv2 in Asia (Kurokawa et al., 2013), NEI in USA (from www.epa.gov/ttnchie1/trends/), EMEP (obtained from www.ceip.at/webdab-emission-database/ emissions-as-used-in-emep-models/) in Europe, and the RETRO database (Schultz et al., 2007) for the rest of the world.

\subsubsection{Seasonal variation}

For the sake of comparison, the IASI HCOOH total columns have been averaged to the horizontal model grid resolution. The IASI and the model total columns have also been averaged by season, defined as December-January-February (DJF), March-April-May (MAM), June-July-August (JJA), and September-October-November (SON) over the 7 years, between 2008 and 2014. Figure 12 presents these global distributions for IASI and the model. For each season, we find that the IASI total columns are higher than those from IMAGESv2 simulations. This highlights the difficulty to predict the measured concentrations by models as found in previous modeling studies such as Stavrakou et al. (2012) and Paulot et al. (2011).

During winter (DJF), the model shows large total columns over equatorial Africa and Asia while IASI only detects large values over Africa.

In spring (MAM), the CTM largely underestimates the distributions over Africa compared to IASI. 

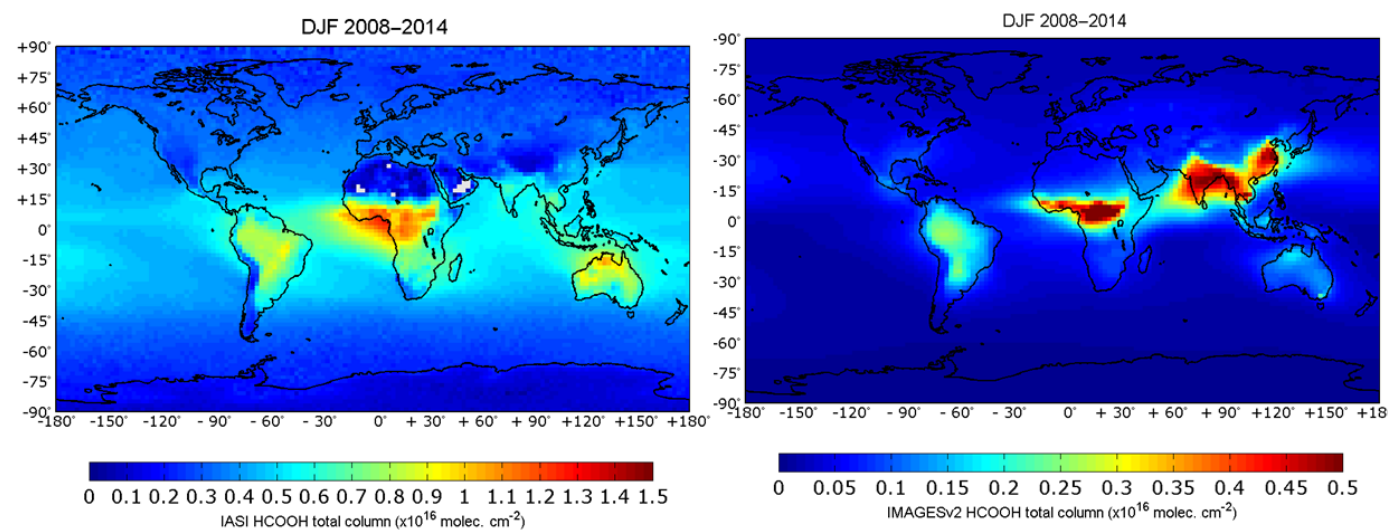

MAM 2008-2014
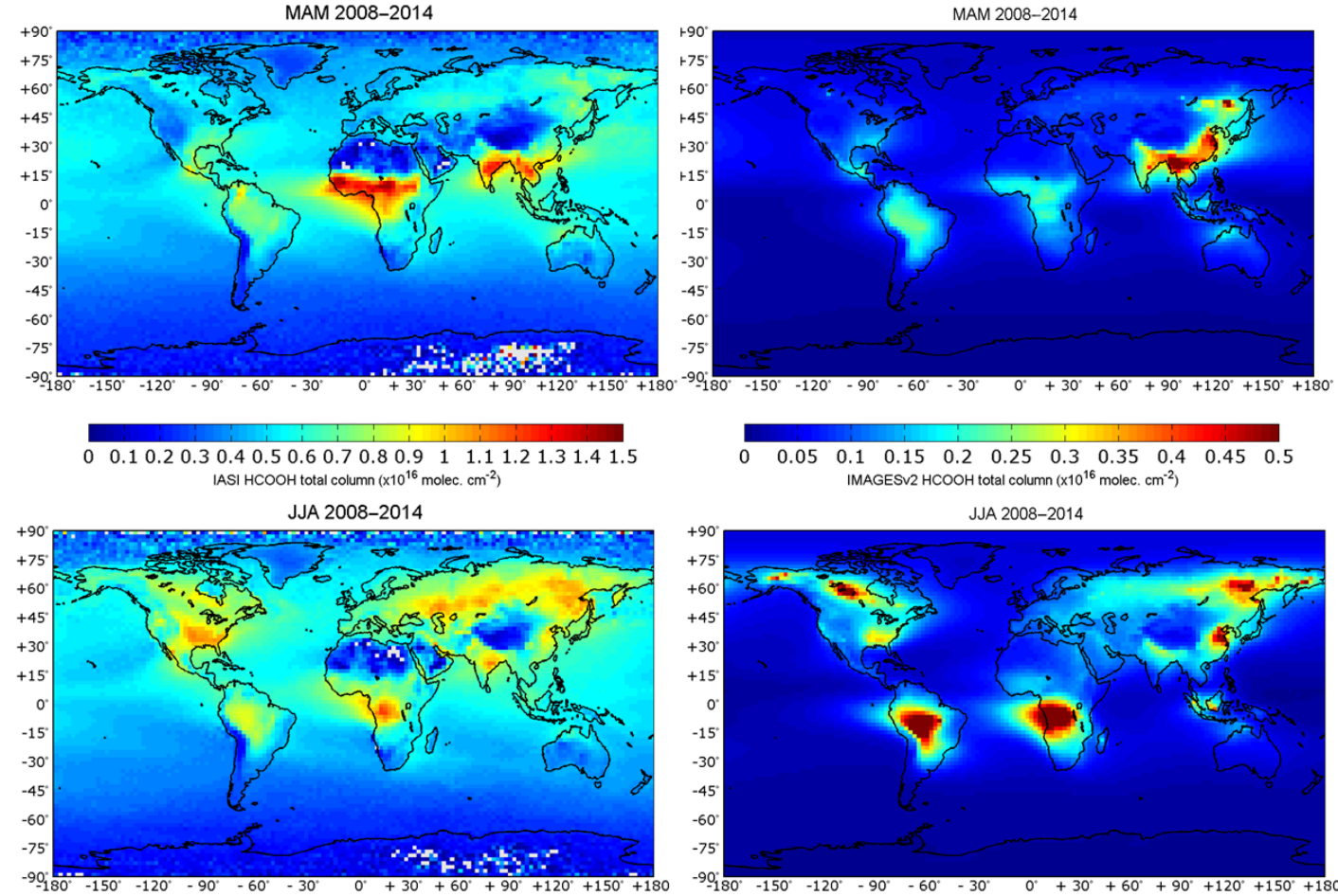

JJA 2008-2014
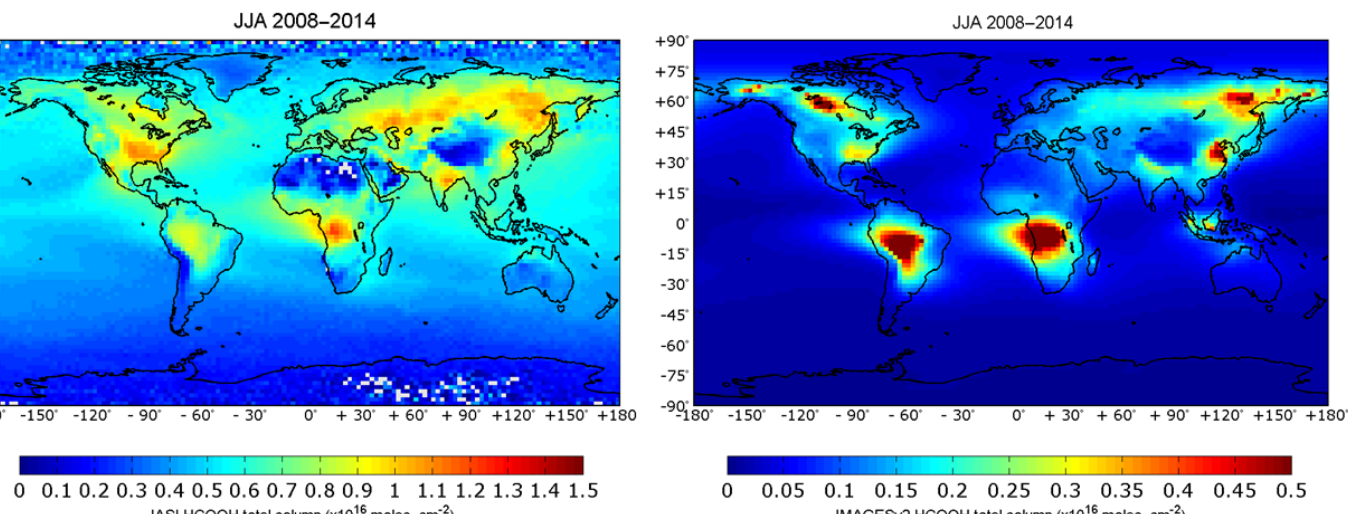
IASI HCOOH total column $\left(\times 10^{16}\right.$ molec. $\left.\mathrm{cm}^{-2}\right)$

SON 2008-2014

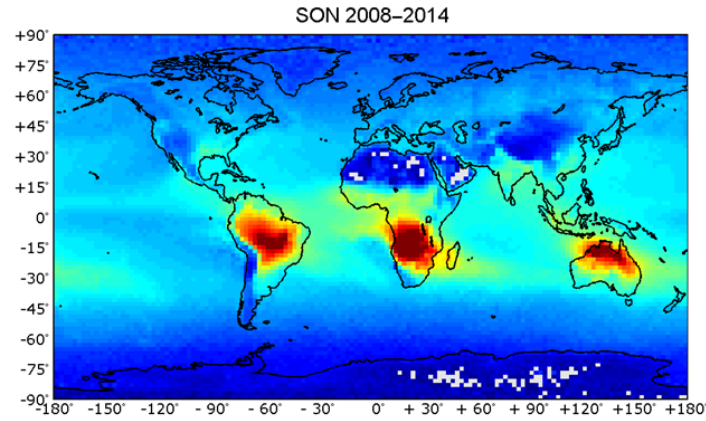

$\begin{array}{lllllllllll}0 & 0.05 & 0.1 & 0.15 & 0.2 & 0.25 & 0.3 & 0.35 & 0.4 & 0.45 & 0.5\end{array}$ IMAGESV2 $\mathrm{HCOOH}$ total column ( $\times 10^{16}$ molec. $\left.\mathrm{cm}^{-2}\right)$

SON 2008-2014

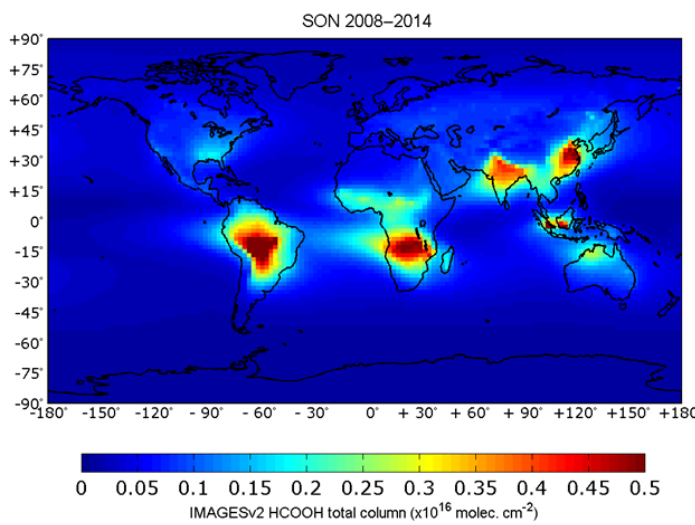

Figure 12. Seasonal HCOOH global distribution from 2008 to 2014 derived using the IASI radiance observations, gridded to IMAGESv2 horizontal resolution ( $2^{\circ}$ lat $\times 2.5^{\circ}$ long) (left panel), and from IMAGESv2 (right panel). DJF is December-January-February; MAM is March-April-May; JJA is June-July-August; SON is September-October-November. Note the different color scale between both distributions. 
In summer (JJA), the emissions from fires seem to be the primary cause for the strong $\mathrm{HCOOH}$ enhancements in the CTM (Africa, Amazonia, boreal regions of Canada and eastern Siberia) although biogenic emissions (southeastern USA) and anthropogenic activities (eastern China) also produce visible enhancements. In the IASI distributions, enhancements associated with fires are less prominent over North and South America. IASI reveals larger total columns over Africa in JJA than over South America while the CTM shows roughly the same values over both regions. Compared with the CTM, IASI also shows larger $\mathrm{HCOOH}$ columns over the Midwestern USA, India, and semiarid regions in southwestern Russia and Kazakhstan.

During fall (SON), the columns from IASI over the southern hemispheric biomass burning emission regions (South America, Africa, and Australia) are larger than over Asia (India and China) and over Indonesia, while those simulated by the model are quite similar for these regions.

\subsubsection{Interannual variation}

The global and seasonal distributions from IASI suggest an underestimation of the modeled columns and a misrepresentation of some emission sources. Figure 13 presents the time series over the areas identified by black boxes in Fig. 1. These regions are AMER (North America), AMAZ (Amazonia), AFRI (Africa), SIBE (Central Siberia), INDI (India), ASIA (Asia), and AUST (Australia).

Over all regions, these time series confirm a large bias of IASI in comparison to the simulations. The seasonal variation is, however, well represented, except over India, where the seasonal cycle is out of phase. This phase difference is coherent with the cycle shown on the global distribution (Fig. 12). The model underestimation over India suggests that either the emission factors of $\mathrm{HCOOH}$ (or its precursors) are underestimated in the model or the biomass burnt estimated by GFEDv3 is too low for this region. The underestimation for forest fire emissions is a severe issue as shown by Chaliyakunnel et al. (2016) over the tropical forests. The calculated linear trend is also provided, based on the annual IASI mean (blue dots in Fig. 13). Over three regions (North America, Africa, and Asia), the trend is negligible $\left(0.2-0.4 \%\right.$ year $\left.^{-1}\right)$ but a small increase is noted over Australia, Amazonia, and India (1.5 \pm 0.5 , $0.9 \pm 0.7$, and $0.7 \pm 0.1 \%$ year $^{-1}$, respectively). A decrease of $0.8 \pm 0.9 \%$ year $^{-1}$ is also observed over Siberia.

Over Amazonia, the large peak in 2010 due to large forest fire emissions (e.g., Hooghiemstra et al., 2012) is well represented in the model and captured by IASI; however, the peak in the IASI data occurs 1 month later than in the CTM. A similar shift was already observed between the $\mathrm{CO}$ and $\mathrm{NH}_{3}$ observations from IASI (Withburn et al., 2015). This $\mathrm{HCOOH}$ shift could be partly due to the difference of altitude in the $\mathrm{HCOOH}$ vertical distributions. IASI detects the plumes in the free troposphere, whereas the IMAGES columns reflect more directly the surface emissions. The mean altitude of the maximum in the $\mathrm{HCOOH}$ vertical profile from the model is located around $2.8 \mathrm{~km}$ for this region and close to $2 \mathrm{~km}$ in August 2010, while the maximum of vertical sensitivity from IASI is located at higher altitudes. This assumes that transport time could be close to 1 month but it is longer than the known mean transport time between the boundary layer and the upper troposphere. Over Siberia, the summer 2010 and to a lesser extent the summer 2012 were exceptional in terms of large $\mathrm{HCOOH}$ emissions, as evident in the global distributions shown in Fig. 8. As revealed by the correlation coefficients, the seasonal cycle is very well captured over Asia $(r=0.75)$, Australia $(r=0.92)$, Siberia $(r=0.94)$, and North America $(r=0.94)$.

The double peaks ( $\sim$ March and September) over Africa are explained by the shift of emission seasons on either side of the Equator. Over Africa, the correlation is lower, due to two factors: there is a shift of 1 month between IASI and the CTM in the maximum of columns and the higher columns from IASI remain longer in time than those simulated (especially between the peak around January with the CTM and the one around February-March for IASI). A difference of altitude in the detection of $\mathrm{HCOOH}$ between the CTM and IASI could not explain IASI detected higher total columns during more than 1 month in the troposphere in March. Around March-April, the mean altitude of maximum in the simulated columns is around $4 \mathrm{~km}$, close to the altitude of maximum vertical sensitivity from IASI, showing that the CTM and IASI should detect the same enriched $\mathrm{HCOOH}$ plume.

\section{Conclusions}

Global distributions of $\mathrm{HCOOH}$ were derived from IASI radiance spectra, using conversion factors between representative retrieved total columns and selected radiance channels $\left(\Delta T_{\mathrm{b}}\right)$. This paper presents 7 years of $\mathrm{HCOOH}$ measurements recorded by IASI. A limitation of this data set is its lack of characterization for vertical sensitivity due to the conversion technique used, even though the maximum sensitivity is shown to be in the mid-troposphere. This approach has the significant advantage of reducing the computing time necessary to analyze large amounts of data and to provide a global representation of the $\mathrm{HCOOH}$ distribution around the world, including ocean and land scenes, and emission sources as well as remote areas.

IASI provides global distributions of $\mathrm{HCOOH}$, highlighting the long-range transport of tropospheric $\mathrm{HCOOH}$ over the Atlantic Ocean and the detection of source regions, e.g., biomass burning areas over Amazonia, Africa, Australia, and Siberia. Other source regions are detected such as the mideastern USA in 2011 or over India.

The comparison with an atmospheric model and, to a lesser extent, with ground-based FTIR observations remains 

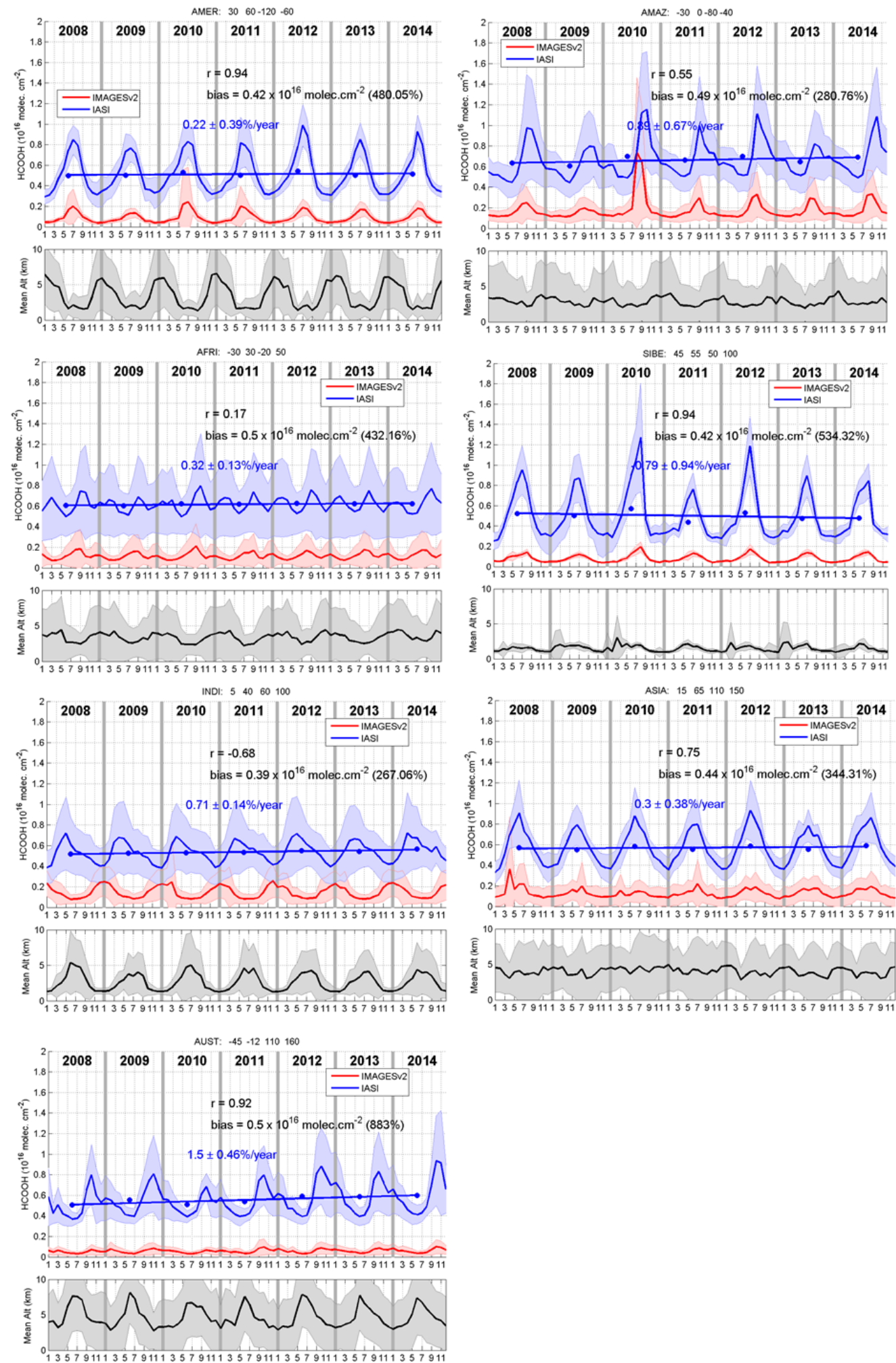

Figure 13. Time series of the monthly HCOOH column means for IASI (blue) and IMAGESv2 (red) over different regions highlighted by black boxes in Fig. 1, between 2008 and 2014. The coordinates of each box (latitude and longitude) are written on the top of each plot. The red and blue shaded areas correspond to the monthly standard deviation. The correlation coefficient, the mean bias, and the normalized mean bias (in parentheses) for the full period are given on each plot. The blue dots correspond to the annual IASI mean. The linear regression on the annual IASI mean and the calculated linear trend are also provided. On the bottom panel, the mean altitude of the maximum in the $\mathrm{HCOOH}$ vertical distribution from IMAGESv2 is plotted in black with the corresponding standard deviation represented by the black shade areas. 
challenging. Despite large biases in many cases, we show that the interannual and the seasonal variations are well captured by IASI when compared with ground-based FTIR measurements and the IMAGESv2 CTM. The best overall correlation with the FTIR is obtained at Saint-Denis over La Réunion $(r=0.77)$ but both sites at La Réunion present the larger biases (>100\% lower than IASI). High correlations are obtained with the CTM, in particularly over America, Australia, Siberia, and Asia, with correlation coefficients ranging from 0.75 to 0.94 . This comparison also points out a misrepresentation of the distribution between IASI and the CTM over India and Africa and a global underestimation of the distribution by the CTM. A small decreasing trend during the 7-year period is observed over Siberia, while a small increase is noted over India, Amazonia, and Australia (0.7, 0.9 , and $1.5 \%$ year $^{-1}$, respectively).

The $\mathrm{HCOOH}$ columns from IASI will require further evaluation and probably improvements to narrow down the biases but the data set available now spans 7 years and it will likely contribute to a better understanding of the tropospheric $\mathrm{HCOOH}$ budget. The data set will be made available through the Ether database (http://ether.ipsl.jussieu.fr) for further scientific studies. This 7-year record will be completed by the data provided by IASI/MetOp-B, launched at the end of 2012, and IASI/MetOp-C, to be launched in 2018. The IASI program will be followed up (after 2022) by the IASI-NG mission aboard the MetOp-SG satellite series (Clerbaux and Crevoisier, 2013; Crevoisier et al., 2014). This new instrument will be characterized by improved spectral resolution and lower radiometric noise. It will lead to a better vertical resolution, along with improved accuracy and detection threshold.

\section{Data availability}

The IASI data are not available yet but as described in the conclusion, the data set will be made available through the Ether database (http://ether.ipsl.jussieu.fr; CNES and INSU, 2016).

\section{The Supplement related to this article is available online} at doi:10.5194/acp-16-8963-2016-supplement.

Acknowledgements. IASI was developed and built under the responsibility of Centre National des Etudes Spatiales (CNES) and flies onboard the MetOp satellite as part of the EUMETSAT Polar system. We thank the Aeris data infrastructure (http://www.aeris-data.fr/) for providing access to the IASI L1C data and to the ECCAD emission inventories used in this study. The French scientists are grateful to CNES for financial support. We also gratefully acknowledge Yasmina R'Honi and
Lieven Clarisse (ULB) for their help with the $\mathrm{HCOOH}$ retrieval. The authors would like to thank the other researchers involved in the ground-based solar remote sensing program at Wollongong (including Nicholas B. Jones, David Griffith, Nicholas Deutscher, and Voltaire Velazco) and the Australian Research Council for its support for the NDACC site at Wollongong, most recently as part of project DP110101948. Acknowledgements are addressed to the Université de La Réunion and CNRS (LACy-UMR8105 and UMS3365) for their support of the OPAR station (Observatoire de Physique de l'Atmosphère de la Réunion). The authors gratefully acknowledge C. Hermans, F. Scolas, and B. Langerock from BIRA-IASB, and J.-M. Metzger from Université de La Réunion for the Réunion Island measurements. The University of Liège contribution to the present work has been supported by the F.R.S. - FNRS, the Belgian Science Policy Office (BELSPO), Brussels, the Fédération Wallonie-Bruxelles, and MeteoSwiss (GAW-CH program). We thank the International Foundation High Altitude Research Stations Jungfraujoch and Gornergrat (HFSJG, Bern). We are grateful to all Belgian colleagues who contributed to the acquisition of the FTIR data at Jungfraujoch. The Réunion Island measurements have mainly been supported by the $\mathrm{A} 3 \mathrm{C}$ project (PRODEX Program of BELSPO). The research was supported by BELSPO and ESA through the IASI.Flow project (Prodex arrangement 4000111403).

Edited by: T. von Clarmann

Reviewed by: two anonymous referees

\section{References}

Andreae, M. O., Andreae, T. W., Talbot, R. W., and Harriss, R. C.: Formic and acetic acid over the central Amazon region, Brazil. I. Dry season, J. Geophys. Res., 93, 1616-1624, doi:10.1029/JD093iD02p01616, 1988.

Andrews, D. U., Heazlewood, B. R., Maccarone, A. T., Conroy, T., Payne, R. J., Jordan, M. J. T., and Kable, S. H.: Phototautomerization of acetaldehyde to vinyl alcohol: a potential route to tropospheric acids, Science, 337, 1203-1206, 2012.

Bohn, B., Siese, M., and Zetzschn, C.: Kinetics of the $\mathrm{OH}+\mathrm{C}_{2} \mathrm{H}_{2}$ reaction in the presence of $\mathrm{O}_{2}$, J. Chem. Soc. Faraday T., 92, 1459-1466, 1996.

Cady-Pereira, K. E., Chaliyakunnel, S., Shephard, M. W., Millet, D. B., Luo, M., and Wells, K. C.: HCOOH measurements from space: TES retrieval algorithm and observed global distribution, Atmos. Meas. Tech., 7, 2297-2311, doi:10.5194/amt-72297-2014, 2014.

Chaliyakunnel, S., Millet, D. B., Wells, K. C., Cady-Pereira, K. E., and Shephard, M. W.: A Large Underestimate of Formic Acid from Tropical Fires: Constraints from SpaceBorne Measurements, Environ. Sci. Technol., 50, 5631-5640, doi:10.1021/acs.est.5b06385, 2016.

Clarisse, L., Coheur, P. F., Prata, A. J., Hurtmans, D., Razavi, A., Phulpin, T., Hadji-Lazaro, J., and Clerbaux, C.: Tracking and quantifying volcanic $\mathrm{SO}_{2}$ with IASI, the September 2007 eruption at Jebel at Tair, Atmos. Chem. Phys., 8, 7723-7734, doi:10.5194/acp-8-7723-2008, 2008. 
Clerbaux, C. and Crevoisier, C.: New Directions: Infrared remote sensing of the troposphere from satellite: Less, but better, Atmos. Environ., 72, 24-26, doi:10.1016/j.atmosenv.2013.01.057, 2013.

Clerbaux, C., Boynard, A., Clarisse, L., George, M., Hadji-Lazaro, J., Herbin, H., Hurtmans, D., Pommier, M., Razavi, A., Turquety, S., Wespes, C., and Coheur, P.-F.: Monitoring of atmospheric composition using the thermal infrared IASI/MetOp sounder, Atmos. Chem. Phys., 9, 6041-6054, doi:10.5194/acp-9-6041-2009, 2009.

Clubb, A. E., Jordan, M. J. T., Kable, S. H., and Osborn, D. L.: Phototautomerization of Acetaldehyde to vinyl alcohol: a primary process in UV-irradiated acetaldehyde from 295 to $335 \mathrm{~nm}$, J. Phys. Chem. Lett., 3, 3522-3526, 2012.

CNES (Centre National dEtudes Spatiales) and INSU (Institut National des Sciences de 1'Univers): Ether database, available at: http://ether.ipsl.jussieu.fr, last access: 15 July 2016.

Coheur, P. F., Clerbaux, C., and Colin, R. : Spectroscopic measurements of halocarbons and hydrohalocarbons by satellite-borne remote sensors, J. Geophys. Res., 108, 4130, doi:10.1029/2002JD002649, 2003.

Coheur, P.-F., Barret, B., Turquety, S., Hurtmans, D., Hadji-Lazaro, J., and Clerbaux, C.: Retrieval and characterization of ozone vertical profiles from a thermal infrared nadir sounder, J. Geophys. Res., 110, D24303, doi:10.1029/2005JD005845, 2005.

Crevoisier, C., Clerbaux, C., Guidard, V., Phulpin, T., Armante, R., Barret, B., Camy-Peyret, C., Chaboureau, J.-P., Coheur, P.F., Crépeau, L., Dufour, G., Labonnote, L., Lavanant, L., HadjiLazaro, J., Herbin, H., Jacquinet-Husson, N., Payan, S., Péquignot, E., Pierangelo, C., Sellitto, P., and Stubenrauch, C.: Towards IASI-New Generation (IASI-NG): impact of improved spectral resolution and radiometric noise on the retrieval of thermodynamic, chemistry and climate variables, Atmos. Meas. Tech., 7, 4367-4385, doi:10.5194/amt-7-4367-2014, 2014.

González Abad, G., Bernath, P. F., Boone, C. D., McLeod, S. D., Manney, G. L., and Toon, G. C.: Global distribution of upper tropospheric formic acid from the ACE-FTS, Atmos. Chem. Phys., 9, 8039-8047, doi:10.5194/acp-9-8039-2009, 2009.

Goode, J., Yokelson, R., Ward, D., Susott, R., Babbitt, R., Davies, M., and Hao, W.: Measurements of excess $\mathrm{O}_{3}, \mathrm{CO}_{2}, \mathrm{CO}, \mathrm{CH}_{4}$, $\mathrm{C}_{2} \mathrm{H}_{4}, \mathrm{C}_{2} \mathrm{H}_{2}, \mathrm{HCN}, \mathrm{NO}, \mathrm{NH}_{3}, \mathrm{HCOOH}, \mathrm{CH}_{3} \mathrm{COOH}, \mathrm{HCHO}$, and $\mathrm{CH}_{3} \mathrm{OH}$ in 1997 Alaskan biomass burning plumes by airborne Fourier transform infrared spectroscopy (AFTIR), J. Geophys. Res., 105, 22147, doi:10.1029/2000JD900287, 2000.

Graedel, T. and Eisner, T.: Atmospheric formic acid from formicine ants: a preliminary assessment, Tellus B, 40, 335-339, 1988.

Grosjean, D.: Organic acids in southern California air: ambient concentrations, mobile source emissions, in situ formation and removal processes, Environ. Sci. Technol., 23, 1506-1514, 1989.

Grutter, M., Glatthor, N., Stiller, G. P., Fischer, H., Grabowski, U., Höpfner, M., Kellmann, S., Linden, A., and von Clarmann, T.: Global distribution and variability of formic acid as observed by MIPAS-ENVISAT, J. Geophys. Res., 115, D10303, doi:10.1029/2009JD012980, 2010.

Hatakeyama, S., Washida, N., and Akimoto, H.: Rate constants and mechanisms for the reaction of hydroxyl (OD) radicals with acetylene, propyne, and 2-butyne in air at $297 \pm 2 \mathrm{~K}$, J. Phys. Chem., 6, 173-178, 1986.
Hooghiemstra, P. B., Krol, M. C., van Leeuwen, T. T., van der Werf, G. R., Novelli, P. C., Deeter, M. N., Aben, I., and Röckmann, T.: Interannual variability of carbon monoxide emission estimates over South America from 2006 to 2010, J. Geophys. Res., 117, D15308, doi:10.1029/2012JD017758, 2012.

Jones, B. T., Muller, J. B. A., O'Shea, S. J., Bacak, A., Le Breton, M., Bannan, T. J., Leather, K. E., Murray Booth, A., Illingworth, S., Bower, K., Gallagher, M. W., Allen, G., Dudley Shallcross, E., Bauguitte, S. J.-B., Pyle, J. A., and Percival, C. J.: Airborne measurements of $\mathrm{HC}(\mathrm{O}) \mathrm{OH}$ in the European Arctic: A winter summer comparison, Atmos. Environ., 99, 556-567, doi:10.1016/j.atmosenv.2014.10.030, 2014.

Kawamura, K., Ng, L., and Kaplan, I.: Determination of organic acids (C1-C10) in the atmosphere, motor exhausts, and engine oils, Environ. Sci. Technol., 19, 1082-1086, 1985.

Keene, W. and Galloway, J.: Organic acidity in precipitation of North America, Atmos. Environ., 18, 2491-2497, 1984.

Keene, W. C. and Galloway, J. N.: The biogeochemical cycling of formic and acetic acids through the troposphere: An overview of current understanding, Tellus B, 40, 322-334, 1988.

Kurokawa, J., Ohara, T., Morikawa, T., Hanayama, S., JanssensMaenhout, G., Fukui, T., Kawashima, K., and Akimoto, H.: Emissions of air pollutants and greenhouse gases over Asian regions during 2000-2008: Regional Emission inventory in ASia (REAS) version 2, Atmos. Chem. Phys., 13, 11019-11058, doi:10.5194/acp-13-11019-2013, 2013.

Lee, A., Goldstein, A. H., Kroll, J. H., Ng, N. L., Varutbangkul, V., Flagan, R. C., and Seinfeld, J. H.: Gas-phase products and secondary aerosol yields from the photooxidation of 16 different terpenes, J. Geophys. Res., 111, D17305, doi:10.1029/2006JD007050, 2006.

Millet, D. B., Baasandorj, M., Farmer, D. K., Thornton, J. A., Baumann, K., Brophy, P., Chaliyakunnel, S., de Gouw, J. A., Graus, M., Hu, L., Koss, A., Lee, B. H., Lopez-Hilfiker, F. D., Neuman, J. A., Paulot, F., Peischl, J., Pollack, I. B., Ryerson, T. B., Warneke, C., Williams, B. J., and Xu, J.: A large and ubiquitous source of atmospheric formic acid, Atmos. Chem. Phys., 15, 6283-6304, doi:10.5194/acp-15-6283-2015, 2015.

Neeb, P., Sauer, F., Horie, O., and Moortgat, G. K.: Formation of hydroxymethyl hydroperoxide and formic acid in alkene ozonolysis in the presence of water vapour, Atmos. Environ., 31, 14171423, 1997.

Ngwabie, N. M., Schade, G. W., Custer, T. G., Linke, S., and Hinz, T.: Abundances and flux estimates of volatile organic compounds from a dairy cowshed in Germany, J. Environ. Qual., 37, 565573, 2008.

Paton-Walsh, C., Jones, N. B., Wilson, S. R., Haverd, V., Meier, A., Griffith, D. W. T., and Rinsland, C. P.: Measurements of trace gas emissions from Australian forest fires and correlations with coincident measurements of aerosol optical depth, J. Geophys. Res.-Atmos., 110, D24305, doi:10.1029/2005JD006202, 2005.

Paulot, F., Wunch, D., Crounse, J. D., Toon, G. C., Millet, D. B., DeCarlo, P. F., Vigouroux, C., Deutscher, N. M., González Abad, G., Notholt, J., Warneke, T., Hannigan, J. W., Warneke, C., de Gouw, J. A., Dunlea, E. J., De Mazière, M., Griffith, D. W. T., Bernath, P., Jimenez, J. L., and Wennberg, P. O.: Importance of secondary sources in the atmospheric budgets of formic and acetic acids, Atmos. Chem. Phys., 11, 1989-2013, doi:10.5194/acp-11-1989-2011, 2011. 
Razavi, A., Karagulian, F., Clarisse, L., Hurtmans, D., Coheur, P. F., Clerbaux, C., Müller, J. F., and Stavrakou, T.: Global distributions of methanol and formic acid retrieved for the first time from the IASI/MetOp thermal infrared sounder, Atmos. Chem. Phys., 11, 857-872, doi:10.5194/acp-11-857-2011, 2011.

R'Honi, Y., Clarisse, L., Clerbaux, C., Hurtmans, D., Duflot, V., Turquety, S., Ngadi, Y., and Coheur, P.-F.: Exceptional emissions of $\mathrm{NH}_{3}$ and $\mathrm{HCOOH}$ in the 2010 Russian wildfires, Atmos. Chem. Phys., 13, 4171-4181, doi:10.5194/acp-13-41712013, 2013.

Rodgers, C. D.: Inverse methods for atmospheric sounding: theory and practice, Ser. Atmos. Ocean. Planet. Phys. 2, World Sci., Hackensack, NJ, USA, 2000.

Rothman, L. S., Gordon, I. E., Barbe, A., Benner, D. C., Bernath, P. F., Birk, M., Boudon, V., Brown, L. R., Campargue, A., Champion, J., Chance, K., Coudert, L. H., Dana, V., Devi, V. M., Fally, S., Flaud, J., Gamache, R. R., Goldman, A., Jacquemart, D., Kleiner, I., Lacome, N., Lafferty, W. J., Mandin, J., Massie, S. T., Mikhailenko, S. N., Miller, C. E., Moazzen-Ahmadi, N., Naumenko, O. V., Nikitin, A. V., Orphal, J., Perevalov, V. I., Perrin, A., Predoi-Cross, A., Rinsland, C. P., Rotger, M., Simeckova, M., Smith, M. A. H., Sung, K., Tashkun, S. A., Tennyson, J., Toth, R. A., Vandaele, A. C., and Vander Auwera, J.: The HITRAN 2008 molecular spectroscopic database, J. Quant. Spectrosc. Ra., 110, 533-572, doi:10.1016/j.jqsrt.2009.02.013, 2009.

Sanhueza, E. and Andreae, M.: Emission of formic and acetic acids from tropical savanna soils, Geophys. Res. Lett., 18, 1707-1710, 1991.

Sanhueza, E., Figueroa, L., and Santana, M.: Atmospheric formic and acetic acids in Venezuela, Atmos. Environ., 30, 1861-1873, 1996.

Schultz, M. G., Backman, L., Balkanski, Y., Bjoerndalsaeter, S., Brand, R., Burrows, J. P., Dalsoeren, S., de Vasconcelos, M., Grodtmann, B., Hauglustaine, D. A., Heil, A., Hoelzemann, J. J., Isaksen, I. S. A., Kaurola, J., Knorr, W., LadstaetterWeißenmayer, A., Mota, B., Oom, D., Pacyna, J., Panasiuk, D., Pereira, J. M. C., Pulles, T., Pyle, J., Rast, S., Richter, A., Savage, N., Schnadt, C., Schulz, M., Spessa, A., Staehelin, J., Sundet, J. K., Szopa, S., Thonicke, K., van het Bolscher, M., van Noije, T., van Velthoven, P., Vik, A. F., and Wittrock, F.: REanalysis of the TROpospheric chemical composition over the past 40 years (RETRO): A long-term global modeling study of tropospheric chemistry, Jülich/Hamburg, Germany, 48/2007 report on Earth System Science of the Max Planck Institute for Meteorology, Hamburg, ISSN 1614-1199, available at: http://retro-archive.iek. fz-juelich.de/data/documents/ (last access: 13 July 2016), 2007.

Sindelarova, K., Granier, C., Bouarar, I., Guenther, A., Tilmes, S., Stavrakou, T., Müller, J.-F., Kuhn, U., Stefani, P., and Knorr, W.: Global data set of biogenic VOC emissions calculated by the MEGAN model over the last 30 years, Atmos. Chem. Phys., 14, 9317-9341, doi:10.5194/acp-14-9317-2014, 2014.

Stavrakou, T., Guenther, A., Razavi, A., Clarisse, L., Clerbaux, C., Coheur, P.-F., Hurtmans, D., Karagulian, F., De Mazière, M., Vigouroux, C., Amelynck, C., Schoon, N., Laffineur, Q., Heinesch, B., Aubinet, M., Rinsland, C., and Müller, J.-F.: First space-based derivation of the global atmospheric methanol emission fluxes, Atmos. Chem. Phys., 11, 4873-4898, doi:10.5194/acp-11-4873-2011, 2011.
Stavrakou, T., Müller, J-F., Peeters, J., Razavi, A., Clarisse, L., Clerbaux, C., Coheur, P.-F., Hurtmans, D., and De Mazière, M.: Satellite evidence for a large source of formic acid from boreal and tropical forests, Nat. Geosci., 5, 26-30, doi:10.1038/ngeo1354, 2012.

Stavrakou, T., Müller, J.-F., Bauwens, M., De Smedt, I., Van Roozendael, M., Guenther, A., Wild, M., and Xia, X.: Isoprene emissions over Asia 1979-2012: impact of climate and land-use changes, Atmos. Chem. Phys., 14, 4587-4605, doi:10.5194/acp14-4587-2014, 2014.

Talbot, R. W., Dibb, J. E., Lefer, B. L., Scheuer, E. M., Bradshaw, J. D., Sandholm, S. T., Smyth, S., Blake, D. R., Blake, N. J., Sachse, G. W., Collins, J. E., and Gregory, G. L.: Large-scale distributions of tropospheric nitric, formic, and acetic acids over the western Pacific basin during wintertime, J. Geophys. Res., 102, 28303-28313, doi:10.1029/96JD02975, 1997a.

Talbot, R. W., Dibb, J. E., Lefer, B. L., Bradshaw, J. D., Sandholm, S. T., Blake, D. R., Blake, N. J., Sachse, G. W., Collins, J. E., Heikes, B. G., Merrill, J. T., Gregory, G. L., Anderson, B. E., Singh, H. B., Thornton, D. C., Bandy, A. R., and Pueschel, R. F.: Chemical characteristics of continental outflow from Asia to the troposphere over the western Pacific Ocean during FebruaryMarch 1994: Results from PEM-West B, J. Geophys. Res., 102, 28255-28274, doi:10.1029/96JD02340, 1997b.

Talbot, R. W., Dibb, J. E., Scheuer, E. M., Blake, D. R., Blake, N. J., Gregory, G. L., Sachse, G. W., Bradshaw, J. D., Sandholm, S T., and Singh, H. B.: Influence of biomass combustion emissions on the distribution of acidic trace gases over the Southern Pacific basin during austral springtime, J. Geophys. Res., 104, 56235634, 1999.

Van Damme, M., Clarisse, L., Heald, C. L., Hurtmans, D., Ngadi, Y., Clerbaux, C., Dolman, A. J., Erisman, J. W., and Coheur, P. F.: Global distributions, time series and error characterization of atmospheric ammonia $\left(\mathrm{NH}_{3}\right)$ from IASI satellite observations, Atmos. Chem. Phys., 14, 2905-2922, doi:10.5194/acp-14-29052014, 2014.

Vander Auwera, J., Didriche, K., Perrin, A., and Keller, F.: Absolute line intensities for formic acid and dissociation constant of the dimer, J. Chem. Phys., 126, 124311, doi:10.1063/1.2712439, 2007.

van der Werf, G. R., Randerson, J. T., Giglio, L., Collatz, G. J., Mu, M., Kasibhatla, P. S., Morton, D. C., DeFries, R. S., Jin, Y., and van Leeuwen, T. T.: Global fire emissions and the contribution of deforestation, savanna, forest, agricultural, and peat fires (19972009), Atmos. Chem. Phys., 10, 11707-11735, doi:10.5194/acp10-11707-2010, 2010.

Vigouroux, C., Stavrakou, T., Whaley, C., Dils, B., Duflot, V., Hermans, C., Kumps, N., Metzger, J.-M., Scolas, F., Vanhaelewyn, G., Müller, J.-F., Jones, D. B. A., Li, Q., and De Mazière, M.: FTIR time-series of biomass burning products $\left(\mathrm{HCN}, \mathrm{C}_{2} \mathrm{H}_{6}\right.$, $\mathrm{C}_{2} \mathrm{H}_{2}, \mathrm{CH}_{3} \mathrm{OH}$, and $\left.\mathrm{HCOOH}\right)$ at Reunion Island $\left(21^{\circ} \mathrm{S}, 55^{\circ} \mathrm{E}\right)$ and comparisons with model data, Atmos. Chem. Phys., 12, 10367-10385, doi:10.5194/acp-12-10367-2012, 2012.

Wallace, J. M. and Hobbs, P. V.: Atmospheric Science: An Introductory Survey, ISBN-13: 978-0127329512, Academic Press, New York, USA, 1977. 
Whitburn, S., Van Damme, M., Kaiser, J. W., van der Werf, G. R., Turquety, S., Hurtmans, D., Clarisse, L., Clerbaux, C., and Coheur, P.-F.: Ammonia emissions in tropical biomass burning regions: Comparison between satellite-derived emissions and bottom-up fire inventories, Atmos. Environ, 121, 42-54, doi:10.1016/j.atmosenv.2015.03.015, 2015.
Zander, R., Duchatelet, P., Mahieu, E., Demoulin, P., Roland, G., Servais, C., Auwera, J. V., Perrin, A., Rinsland, C. P., and Crutzen, P. J.: Formic acid above the Jungfraujoch during 1985-2007: observed variability, seasonality, but no long-term background evolution, Atmos. Chem. Phys., 10, 10047-10065, doi:10.5194/acp-10-10047-2010, 2010. 